New Astronomy Vol. 15 (5): 417-426 (2010)

ISSN: (print 1384-1076)(online 1384-1092)

doi:10.1016/j.newast.2009.11.010

This is a peer-reviewed pre-print version of the following article: Photoionization and electron-ion recombination of He I, which has been published in final form at:

http://www.elsevier.com

http://www.elsevier.com/locate/newast

http://www.sciencedirect.com/science/article/pii/S1384107609001699

(C) 2010 Elsevier BV

\title{
Photoionization and electron-ion recombination of He I
}

\section{Sultana N. Nahar, Department of Astronomy, The Ohio State University, Columbus, OH 43210, United States}

\begin{abstract}
Results from the unified method for photoionization and electron-ion recombination of (He $\mathrm{I}+\mathrm{hv} \leftrightarrow \mathrm{He} \mathrm{II}+\mathrm{e}$ ) are presented. He I wave function is represented by an expansion that includes 10 core states for excitations to $n=2,3$, and 4 states. A total of 99 bound LS states with $n \leq 10$ are obtained. They all, except two, agree with the observed energies in less than $1 \%$. Photoionization cross sections $\sigma_{\mathrm{PI}}$ for the total ionization, leaving the residual ion in all excited states, and the partial ionization, leaving the ion in the ground state, are presented for all 99 bound states. Calculated $\sigma_{P I}$ agree very well with the measured ground state cross section. Detailed resonant features of $\sigma_{\mathrm{PI}}$ and coupling effects on the background cross sections are illustrated. For the recombination process, state-specific and total recombination rate coefficients are presented. These include both the radiative and dielectronic recombination processes. In addition, the total recombination spectrum with electron energy is presented and exhibits the resonant features that were observed experimentally. Recombination rates for hydrogenic He II is also presented. The present results obtained in LS coupling approximation provide a unified and self-consistent sets of results for astrophysical modelings of the two inverse radiative processes until highly accurate and precise results will be available through comprehensive relativistic calculations.
\end{abstract}

\section{Introduction}

Being the earliest primordial element with $24 \%$ abundance, helium is of crucial interest astrophysically. In structure, it is the simplest element after hydrogen. However, study of this element is more difficult than any other He-like ions. The main reason is the construction of an accurate wave function. Helium wave function decays slowly and hence is extended over a large distance and an extensive representation of the atom is required to avoid the numerical instabilities. Being a neutral it is also sensitive to various effects, such as polarization, relativistic, and QED. While this element has been studied extensively, for the most accurate energies by Drake and collaborators (e.g. Drake and Martin, 1998; Drake and Morton, 2007) and radiative decay rates by Dalgarno and collaborators (e.g. Dalgarno and Lynn, 1957) and a few others, atomic processes, such as photoionization, electron-ion recombination, are still under investigation for high precision parameters. The present work reports study of two important inverse radiative processes of photoionization and electron-ion recombination in an ab initio manner using unified method based on the R-matrix method and close coupling approximation. The unified method includes both the radiative recombination (RR) and dielectronic 
recombination (DR).

Earlier studies on photoionization concentrated in the low-energy non-resonant background features, such as, experimentally by Samson (1976), theoretically by Wendin (1970, 1971), Miller and Starace (1980), Hummer and Storey (1998) and others. However, much less results are available for the resonant structures. Photoionization of He I detailed with autoionizing resonances was studied under the Opacity Project $(1995,1996)$ by Fernley et al. (1987). They obtained only the total photoionization cross sections for a relatively large number of states. However, present work provides a more complete work on photoionization by using a larger wave function and considering larger number of bound states, and includes the process of electron-ion recombination.

Earlier works on electron-ion recombination, separately for radiative recombination and dielectronic recombination, were carried out by investigators, such as, Burgess and Seaton (1961), Burgess (1965), Aldrovandi and Pequignot (1973), Pequignot et al. (1991), Hummer and Storey (1998), and DR spectrum was measured experimentally by Tanabe et al. (1991), DeWitt et al. (1994).

\section{Theory}

The processes of photoionization and electron-ion recombination are studied using the unified method of Nahar and Pradhan (1992a, 1994) which is based on the close coupling (CC) approximation and R-matrix method as implemented under the Opacity Project (OP) $(1995,1996)$ and the Iron Project (IP) (Hummer et al., 1993). A brief outline of the theory is given below.

The CC approximation describes the atomic system of an ion and an interacting electron as the 'target' or the 'core' of $N$ electrons interacting with the $(N+1)$ th electron. The interacting $(N+$ 1)th electron may be bound or in the continuum depending on its energy (E) being negative or positive. The total wavefunction, $\Psi_{\mathrm{E}}$, of the $(N+1)$ electron system in a symmetry SL $\pi$ is expressed by the expansion,

$$
\Psi_{E}(e+i o n)=A \sum_{i} \chi_{i}(i o n) \theta_{i}+\sum_{j} c_{j} \Phi_{j}
$$

where $\chi_{i}$ is the target or the core ion eigenfunction which is coupled with the $(N+1)$ th electron function, $\theta_{i}$. The sum is over the ground and various excited core states. The $(N+1)$ th electron with kinetic energy $k_{i}^{2}$ is in a channel labeled as $S_{i} L_{i} \pi_{i} k_{i}^{2} 1_{i}(\mathrm{SL} \pi)$. The second sum contains bound channel functions $\Phi_{j} s$ of the $(N+1)$-electron system and accounts for short range correlation and the orthogonality between the continuum and the bound electron orbitals. The present calculations were carried out in LS coupling approximation. Hence the Hamiltonian of the $(\mathrm{N}+1)$-electron system is given by

$$
H_{N+1}=\sum_{i=1}^{N+1}\left\{-\nabla_{i}^{2}-\frac{2 Z}{r_{i}}+\sum_{j>i}^{N+1} \frac{2}{r_{i j}}\right\}
$$

Substitution of $\Psi_{E}(e+i o n)$ in the Schrodinger equation

$$
H_{N+1} \Psi_{E}=E \Psi_{E}
$$

introduces a set of coupled equations that are solved using the R-matrix method. The solution is a continuum wave function, $\Psi_{F}$, for an electron with positive energies $(E>0)$, or a bound state, $\Psi_{B}$, at a negative total energy $(E \leq 0)$. The complex resonant structures in photoionization or recombination result from couplings between the continuum channels that are open $\left(k_{i}^{2}>0\right)$ and bound channels that are closed $\left(k_{i}^{2}<0\right)$ at electron energies $k_{i}^{2}$ corresponding to autoionizing 
states of the Rydberg series, $S_{i} L_{i} \pi_{i} v$ l, where $v$ is the effective quantum number, belonging to excited target or core state $S_{i} L_{i} \pi_{i}$.

The reduced matrix element for transition for photoionization is $\left\langle\Psi_{B}\|\mathbf{D}\| \Psi_{F}\right\rangle$ where $\mathbf{D}=$ $\sum_{\mathrm{i}} \mathrm{r}_{\mathrm{i}}$ is the dipole operator and the sum is over the number of electrons. The dipole transition matrix element is reduced to generalized line strength as

$$
\mathbf{S}=\mid\left\langle\left.\Psi_{j}\|\mathbf{D}\| \Psi_{i}\right|^{2}=\left|\left\langle\psi_{f}\left|\sum_{j=1}^{N+1} \mathrm{r}_{j}\right| \psi_{i}\right\rangle\right|^{2},\right.
$$

where $\Psi_{i}$ and $\Psi_{f}$ are the initial and final state wave functions. The photoionization cross section $\left(\sigma_{\mathrm{PI}}\right)$ is proportional to the generalized line strength,

$$
\sigma_{P l}=\frac{4 \pi^{2}}{3 c} \frac{1}{g_{i}} \omega \mathbf{S}
$$

where $\mathrm{g}_{\mathrm{i}}$ is the statistical weight factor of the bound state and $\omega$ is the incident photon energy. The details for calculations of photoionization in the R-matrix method and CC approximation can be found in Seaton (1987a) and Berrington et al. (1987).

The unified method for the total electron-ion recombination (Nahar and Pradhan, 1992a, 1994) considers both the radiative recombination and dielectronic recombination in a unified manner and provides self-consistent sets of cross sections for the inverse processes of electron-ion recombination and photoionization. It divides the infinite number of recombined states into two groups for calculations: group (A) states with $n \leq n_{o}$ and group (B) states with $n_{o}<n \leq \infty$, where $n_{o}$ $\sim 10$. For group (A) states, unified method obtains recombination cross sections, $\sigma_{R C}$, from partial photoionization cross section by using the principle of detailed balance or Milne relation,

$$
\sigma_{R C}=\sigma_{\rho} \frac{g_{i}}{g_{j}} \frac{h^{2} \omega^{2}}{4 \pi^{2} m^{2} c^{2} v^{2}}
$$

where $\mathrm{g}_{\mathrm{j}}$ is the statistical weight factor of the recombined state and $v$ is the photoelectron velocity. The recombining ion is assumed to be in the ground state. The detailed autoionizing structures in photoionization cross sections are integrated into the recombination cross sections through the Milne relation. Hence the cross section corresponds to inclusion of both the RR and DR in an unified and $a b$ initio manner. The state-specific recombination rate coefficient of state $i$ is obtained by averaging the recombination cross sections over the Maxwellian electron distribution, $f(v)$ $=\frac{4}{\sqrt{\pi}}\left(\frac{m}{2 k T}\right)^{3 / 2} v^{2} e^{-\frac{m v^{2}}{2 k T}}$, as

\begin{tabular}{llllllll}
\hline & Config. & Term & $\mathrm{E}(\mathrm{Ry})$ & & Config. & Term & $\mathrm{E}(\mathrm{Ry})$ \\
\hline 1 & $1 \mathrm{~s}$ & ${ }^{2} \mathrm{~S}$ & 0.00 & 6 & $3 \mathrm{~s}$ & ${ }^{2} \mathrm{~S}$ & 3.5556 \\
2 & $2 \mathrm{~s}$ & ${ }^{2} \mathrm{~S}$ & 3.0 & 7 & $4 \mathrm{f}$ & ${ }^{2} \mathrm{~F}^{\mathrm{o}}$ & 3.75 \\
3 & $2 \mathrm{p}$ & ${ }^{2} \mathrm{P}^{\mathrm{o}}$ & 3.0 & 8 & $4 \mathrm{~d}$ & ${ }^{2} \mathrm{D}$ & 3.75 \\
4 & $3 \mathrm{~d}$ & ${ }^{2} \mathrm{D}$ & 3.5556 & 9 & $4 \mathrm{p}$ & ${ }^{2} \mathrm{P}^{\mathrm{o}}$ & 3.75 \\
5 & $3 \mathrm{p}$ & ${ }^{2} \mathrm{P}^{0}$ & 3.5556 & 10 & $4 \mathrm{~s}$ & ${ }^{2} \mathrm{~S}$ & 3.75 \\
\hline
\end{tabular}

Table 1 Terms and energies of target He II in the eigenfunction expansion of He I.

\begin{tabular}{llllllll}
\hline Conf. & Term & $E_{o}(\mathrm{Ry})$ & $E_{c}(\mathrm{Ry})$ & Conf. & Term & $E_{o}(\mathrm{Ry})$ & $E_{\mathrm{c}}(\mathrm{Ry})$ \\
\hline $1 \mathrm{~s} 2$ & ${ }^{1} \mathrm{~S}^{\mathrm{e}}$ & 1.80714 & 1.77376 & $1 \mathrm{~s} 2 \mathrm{~s}$ & ${ }^{3} \mathrm{~S}^{\mathrm{e}}$ & 0.35043 & 0.35030 \\
$1 \mathrm{~s} 2 \mathrm{~s}$ & ${ }^{1} \mathrm{~S}^{\mathrm{e}}$ & 0.29191 & 0.28900 & $1 \mathrm{~s} 2 \mathrm{p}$ & ${ }^{3} \mathrm{P}^{\mathrm{o}}$ & 0.26631 & 0.26557
\end{tabular}




\begin{tabular}{|c|c|c|c|c|c|c|c|}
\hline $1 \mathrm{~s} 2 \mathrm{p}$ & ${ }^{1} \mathrm{P}^{\mathrm{o}}$ & 0.24764 & 0.24697 & $1 \mathrm{~s} 3 \mathrm{~s}$ & ${ }^{3} \mathrm{~S}^{\mathrm{e}}$ & 0.13736 & 0.13734 \\
\hline $1 \mathrm{~s} 3 \mathrm{~s}$ & ${ }^{1} S^{e}$ & 0.12253 & 0.12170 & $1 s 3 p$ & ${ }^{3} \mathrm{P}^{\mathrm{o}}$ & 0.11615 & 0.11592 \\
\hline $1 \mathrm{~s} 3 \mathrm{~d}$ & ${ }^{3} \mathrm{D}^{\mathrm{e}}$ & 0.11126 & 0.11126 & $1 \mathrm{~s} 3 \mathrm{~d}$ & ${ }^{1} \mathrm{D}^{\mathrm{e}}$ & 0.11123 & 0.11123 \\
\hline $1 \mathrm{~s} 3 \mathrm{p}$ & ${ }^{1} \mathrm{P}^{0}$ & 0.11028 & 0.11005 & $1 \mathrm{~s} 4 \mathrm{~s}$ & ${ }^{3} \mathrm{~S}^{\mathrm{e}}$ & 0.07302 & 0.07300 \\
\hline $1 \mathrm{~s} 4 \mathrm{~s}$ & ${ }^{1} S^{e}$ & 0.06716 & 0.06682 & $1 \mathrm{~s} 4 \mathrm{p}$ & ${ }^{3} \mathrm{P}^{0}$ & 0.06464 & 0.06455 \\
\hline $1 \mathrm{~s} 4 \mathrm{~d}$ & ${ }^{3} \mathrm{D}^{\mathrm{e}}$ & 0.06257 & 0.06257 & $1 \mathrm{~s} 4 \mathrm{~d}$ & ${ }^{1} D^{e}$ & 0.06255 & 0.06255 \\
\hline $1 \mathrm{~s} 4 \mathrm{f}$ & ${ }^{3} \mathrm{~F}^{\mathrm{o}}$ & 0.06250 & 0.06251 & $1 \mathrm{~s} 4 \mathrm{f}$ & ${ }^{1} \mathrm{~F}^{\mathrm{o}}$ & 0.06250 & 0.06251 \\
\hline $1 \mathrm{~s} 4 \mathrm{p}$ & ${ }^{1} \mathrm{P}^{0}$ & 0.06213 & 0.06203 & $1 \mathrm{~s} 5 \mathrm{~s}$ & ${ }^{3} \mathrm{~S}^{\mathrm{e}}$ & 0.04523 & 0.04524 \\
\hline $1 \mathrm{~s} 5 \mathrm{~s}$ & ${ }^{1} S^{e}$ & 0.04235 & 0.04218 & $1 \mathrm{~s} 5 \mathrm{p}$ & ${ }^{3} \mathrm{P}^{0}$ & 0.04110 & 0.04105 \\
\hline $1 \mathrm{~s} 5 \mathrm{~d}$ & ${ }^{3} \mathrm{D}^{\mathrm{e}}$ & 0.04004 & 0.04004 & $1 \mathrm{~s} 5 \mathrm{~d}$ & ${ }^{1} \mathrm{D}^{\mathrm{e}}$ & 0.04003 & 0.04003 \\
\hline $1 \mathrm{~s} 5 \mathrm{f}$ & ${ }^{3} \mathrm{~F}^{0}$ & 0.04000 & 0.04001 & $1 \mathrm{~s} 5 \mathrm{f}$ & ${ }^{1} \mathrm{~F}^{0}$ & 0.04000 & 0.04001 \\
\hline $1 \mathrm{~s} 5 \mathrm{~g}$ & ${ }^{3} \mathrm{G}^{\mathrm{e}}$ & 0.04000 & 0.04000 & $1 \mathrm{~s} 5 \mathrm{~g}$ & ${ }^{1} \mathrm{G}^{\mathrm{e}}$ & 0.04000 & 0.04000 \\
\hline $1 s 5 p$ & ${ }^{1} \mathrm{P}^{\mathrm{o}}$ & 0.03981 & 0.03975 & $1 \mathrm{~s} 6 \mathrm{~s}$ & ${ }^{3} \mathrm{~S}^{\mathrm{e}}$ & 0.03075 & 0.03075 \\
\hline $1 \mathrm{~s} 6 \mathrm{~s}$ & ${ }^{1} \mathrm{~S}^{\mathrm{e}}$ & 0.02912 & 0.02902 & $1 \mathrm{~s} 6 \mathrm{p}$ & ${ }^{3} \mathrm{P}^{0}$ & 0.02841 & 0.02839 \\
\hline $1 \mathrm{~s} 6 \mathrm{~d}$ & ${ }^{3} \mathrm{D}^{\mathrm{e}}$ & 0.02780 & 0.02780 & $1 \mathrm{~s} 6 \mathrm{~d}$ & ${ }^{1} D^{e}$ & 0.02779 & 0.02779 \\
\hline $1 \mathrm{~s} 6 \mathrm{f}$ & ${ }^{3} \mathrm{~F}^{0}$ & 0.02778 & 0.02778 & $1 \mathrm{~s} 6 \mathrm{f}$ & ${ }^{1} \mathrm{~F}^{0}$ & 0.02778 & 0.02778 \\
\hline $1 \mathrm{~s} 6 \mathrm{~g}$ & ${ }^{3} \mathrm{G}^{\mathrm{e}}$ & 0.02778 & 0.02778 & $1 \mathrm{~s} 6 \mathrm{~g}$ & ${ }^{1} G^{e}$ & 0.02778 & 0.02778 \\
\hline $1 \mathrm{~s} 6 \mathrm{~h}$ & ${ }^{3} \mathrm{H}^{\mathrm{o}}$ & 0.02777 & 0.02778 & $1 \mathrm{~s} 6 \mathrm{~h}$ & ${ }^{1} \mathrm{H}^{\mathrm{o}}$ & 0.02777 & 0.02778 \\
\hline $1 \mathrm{~s} 6 \mathrm{p}$ & ${ }^{1} \mathrm{P}^{\mathrm{o}}$ & 0.02766 & 0.02763 & $1 \mathrm{~s} 7 \mathrm{~s}$ & ${ }^{3} \mathrm{~S}^{\mathrm{e}}$ & 0.02226 & 0.02225 \\
\hline $1 \mathrm{~s} 7 \mathrm{~s}$ & ${ }^{1} S^{e}$ & 0.02125 & 0.02119 & $1 \mathrm{~s} 7 \mathrm{p}$ & ${ }^{3} \mathrm{P}^{0}$ & 0.02081 & 0.02079 \\
\hline $1 \mathrm{~s} 7 \mathrm{~d}$ & ${ }^{3} D^{e}$ & 0.02042 & 0.02042 & $1 \mathrm{~s} 7 \mathrm{~d}$ & ${ }^{1} D^{e}$ & 0.02042 & 0.02042 \\
\hline $1 \mathrm{~s} 7 \mathrm{f}$ & ${ }^{3} \mathrm{~F}^{\mathrm{O}}$ & 0.02041 & 0.02041 & $1 \mathrm{~s} 7 \mathrm{f}$ & ${ }^{1} \mathrm{~F}^{\mathrm{o}}$ & 0.02041 & 0.02041 \\
\hline $1 \mathrm{~s} 7 \mathrm{~g}$ & ${ }^{3} \mathrm{G}^{\mathrm{e}}$ & 0.02041 & 0.02041 & $1 \mathrm{~s} 7 \mathrm{~g}$ & ${ }^{1} \mathrm{G}^{\mathrm{e}}$ & 0.02041 & 0.02041 \\
\hline $1 \mathrm{~s} 7 \mathrm{~h}$ & ${ }^{3} \mathrm{H}^{0}$ & 0.02041 & 0.02041 & $1 \mathrm{~s} 7 \mathrm{~h}$ & ${ }^{1} \mathrm{H}^{\mathrm{o}}$ & 0.02041 & 0.02041 \\
\hline $1 \mathrm{~s} 7 \mathrm{i}$ & ${ }^{3} \mathrm{I}^{\mathrm{e}}$ & 0.02041 & 0.02041 & $1 \mathrm{~s} 7 \mathrm{i}$ & ${ }^{1} \mathrm{I}^{\mathrm{e}}$ & 0.02041 & 0.02041 \\
\hline $1 \mathrm{~s} 7 \mathrm{p}$ & ${ }^{1} \mathrm{P}^{\mathrm{o}}$ & 0.02034 & 0.02032 & $1 \mathrm{~s} 8 \mathrm{~s}$ & ${ }^{3} \mathrm{~S}^{\mathrm{e}}$ & 0.01685 & 0.01685 \\
\hline $1 \mathrm{~s} 8 \mathrm{~s}$ & ${ }^{1} S^{e}$ & 0.01619 & 0.01614 & $1 \mathrm{~s} 8 \mathrm{p}$ & ${ }^{3} \mathrm{P}^{0}$ & 0.01589 & 0.01588 \\
\hline $1 \mathrm{~s} 8 \mathrm{~d}$ & ${ }^{3} \mathrm{D}^{\mathrm{e}}$ & 0.01563 & 0.01563 & $1 \mathrm{~s} 8 \mathrm{~d}$ & ${ }^{1} D^{e}$ & 0.01563 & 0.01563 \\
\hline $1 \mathrm{~s} 8 \mathrm{f}$ & ${ }^{3} \mathrm{~F}^{\mathrm{o}}$ & 0.01562 & 0.01563 & $1 \mathrm{~s} 8 \mathrm{f}$ & ${ }^{1} \mathrm{~F}^{\mathrm{o}}$ & 0.01562 & 0.01563 \\
\hline $1 \mathrm{~s} 8 \mathrm{~g}$ & ${ }^{3} G^{e}$ & 0.01562 & 0.01563 & $1 \mathrm{~s} 8 \mathrm{~g}$ & ${ }^{1} G^{e}$ & 0.01562 & 0.01563 \\
\hline $1 \mathrm{~s} 8 \mathrm{~h}$ & ${ }^{3} \mathrm{H}^{\mathrm{o}}$ & 0.01562 & 0.01563 & $1 \mathrm{~s} 8 \mathrm{~h}$ & ${ }^{1} \mathrm{H}^{\mathrm{o}}$ & 0.01562 & 0.01563 \\
\hline $1 \mathrm{~s} 8 \mathrm{i}$ & ${ }^{3} \mathrm{I}^{\mathrm{e}}$ & 0.01562 & 0.01562 & $1 \mathrm{~s} 8 \mathrm{i}$ & ${ }^{1} \mathrm{I}^{\mathrm{e}}$ & 0.01562 & 0.01562 \\
\hline $1 \mathrm{~s} 8 \mathrm{k}$ & ${ }^{3} \mathrm{~K}^{0}$ & 0.01562 & 0.01562 & $1 \mathrm{~s} 8 \mathrm{p}$ & ${ }^{1} \mathrm{P}^{\mathrm{o}}$ & 0.01558 & 0.01556 \\
\hline $1 \mathrm{~s} 9 \mathrm{~s}$ & ${ }^{3} S^{e}$ & 0.01320 & 0.01320 & $1 \mathrm{~s} 9 \mathrm{~s}$ & ${ }^{1} S^{e}$ & 0.01274 & 0.01271 \\
\hline $1 \mathrm{~s} 9 \mathrm{p}$ & ${ }^{3} \mathrm{P}^{\mathrm{o}}$ & 0.01253 & 0.01252 & $1 \mathrm{~s} 9 \mathrm{~d}$ & ${ }^{3} \mathrm{D}^{\mathrm{e}}$ & 0.01235 & 0.01235 \\
\hline $1 \mathrm{~s} 9 \mathrm{~d}$ & ${ }^{1} \mathrm{D}^{\mathrm{e}}$ & 0.01235 & 0.01235 & $1 \mathrm{~s} 9 \mathrm{f}$ & ${ }^{3} \mathrm{~F}^{0}$ & 0.01235 & 0.01235 \\
\hline
\end{tabular}




\begin{tabular}{llllllll}
$1 \mathrm{~s} 9 \mathrm{f}$ & ${ }^{1} \mathrm{~F}^{0}$ & 0.01235 & 0.01235 & $1 \mathrm{~s} 9 \mathrm{~g}$ & ${ }^{3} \mathrm{G}^{\mathrm{e}}$ & 0.01234 & 0.01235 \\
$1 \mathrm{~s} 9 \mathrm{~g}$ & ${ }^{1} \mathrm{G}^{\mathrm{e}}$ & 0.01234 & 0.01235 & $1 \mathrm{~s} 9 \mathrm{~h}$ & ${ }^{3} \mathrm{H}^{\mathrm{o}}$ & 0.01234 & 0.01235 \\
$1 \mathrm{~s} 9 \mathrm{~h}$ & ${ }^{1} \mathrm{H}^{\mathrm{o}}$ & 0.01234 & 0.01235 & $1 \mathrm{~s} 9 \mathrm{i}$ & ${ }^{3} \mathrm{I}^{\mathrm{e}}$ & 0.01234 & 0.01235 \\
$1 \mathrm{~s} 9 \mathrm{i}$ & ${ }^{1} \mathrm{I}^{\mathrm{e}}$ & 0.01234 & 0.01235 & $1 \mathrm{~s} 9 \mathrm{k}$ & ${ }^{3} \mathrm{~K}^{\mathrm{o}}$ & 0.01234 & 0.01235 \\
$1 \mathrm{~s} 9 \mathrm{p}$ & ${ }^{1} \mathrm{P}^{\mathrm{o}}$ & 0.01231 & 0.01230 & $1 \mathrm{~s} 10 \mathrm{~s}$ & ${ }^{3} \mathrm{~S}^{\mathrm{e}}$ & 0.01062 & 0.01062 \\
\hline
\end{tabular}

Table 2 Comparison of calculated LS term energies, $E_{c}$, of He I with the term energies, $E_{o}$, obtained from statistical averaging of the fine structure level energies at NIST (NIST).

$$
\alpha_{R}(i ; T)=\int_{0}^{\infty} v f(v) \sigma_{R}(i) d v
$$

The total recombination rate is then obtained from the sum of these individual rates, that is, $\alpha_{R}(T)$ $=\sum_{i} \alpha_{R}(\mathrm{i}, T)$ where the sum is over the recombined states. The group (A) states are more separable than group (B) states. Most of the contributions for the total recombination cross sections and rate coefficients come from Group (A) states.

The highly excited states of group (B) lie close together in a small energy region below each excited core threshold and the resonances become narrower with higher $n$. Recombination into group (B) states, is dominated by DR via high- $n$ resonances while the background recombination, that is, RR is negligibly small. Bell and Seaton (1985) developed a precise treatment for the DR process based on quantum defect theory and close coupling approximation and obtained an expression for the averaged DR probability which in an entrance channel $\alpha$ is given by

$$
P_{\alpha}(D R)=\left(1-\mathscr{S}_{e e}^{i} \mathscr{S}_{e e}\right)_{\alpha}
$$

$\mathscr{S}_{\mathrm{ee}}$ is the electron scattering matrix including radiation damping. The mathematical steps were extended by Nahar and Pradhan (1994) for calculations of DR collision strength $\Omega(D R)$ as described in their paper. $\Omega(D R)$ is obtained as

$$
\Omega(D R)=\sum_{S L \pi} \sum_{n} \frac{1}{2}(2 S+1)(2 L+1) P_{n}^{S L \pi}(D R)
$$

The values of $\Omega(\mathrm{DR})$ are obtained in the CC approximation using the same wave function expansion used for photoionization cross sections. $\Omega(\mathrm{DR})$ is summed over all contributing symmetries SL $\pi$. The recombination cross section is obtained as,

$$
\sigma_{R C}(D R)=\frac{\pi}{g_{i} k^{2}} \Omega(D R) a_{0}^{2},
$$

The total DR contributions of $n>10$ states is much smaller than that for $n<10$ states except at the DR peak. The RR-type 'back ground' contributions from the high- $n$ group (B) states are included in hydrogenic approximation (Nahar, 1996). These contributions are usually negligible except at very low temperatures.

The spectrum for the recombination rate coefficients with photoelectron energy can be measured. Such spectra can be produced from unified total recombination cross sections $\sigma_{\mathrm{RC}}(E)$ as,

$$
\alpha_{R}(E)=v \sigma_{R C}(E)
$$

where $v$ is the photoelectron energy. Since $\alpha_{R}(E)$ is proportional to $\sigma_{R C}(E)$, the detailed resonant features are similar and can be observed in the electron-ion recombination spectrum. The features 
are of considerable interest for experimental measurements and provide the scope to benchmark theory and experiment.

\section{Computations}

The computations for the inverse processes of photoionization and electron-ion recombination were carried out through various stages of the R-matrix package of codes (Berrington et al., 1987; Nahar and Pradhan, 1994, 1995) developed under the Opacity Project (1995, 1996). The first step was to obtain the target or core

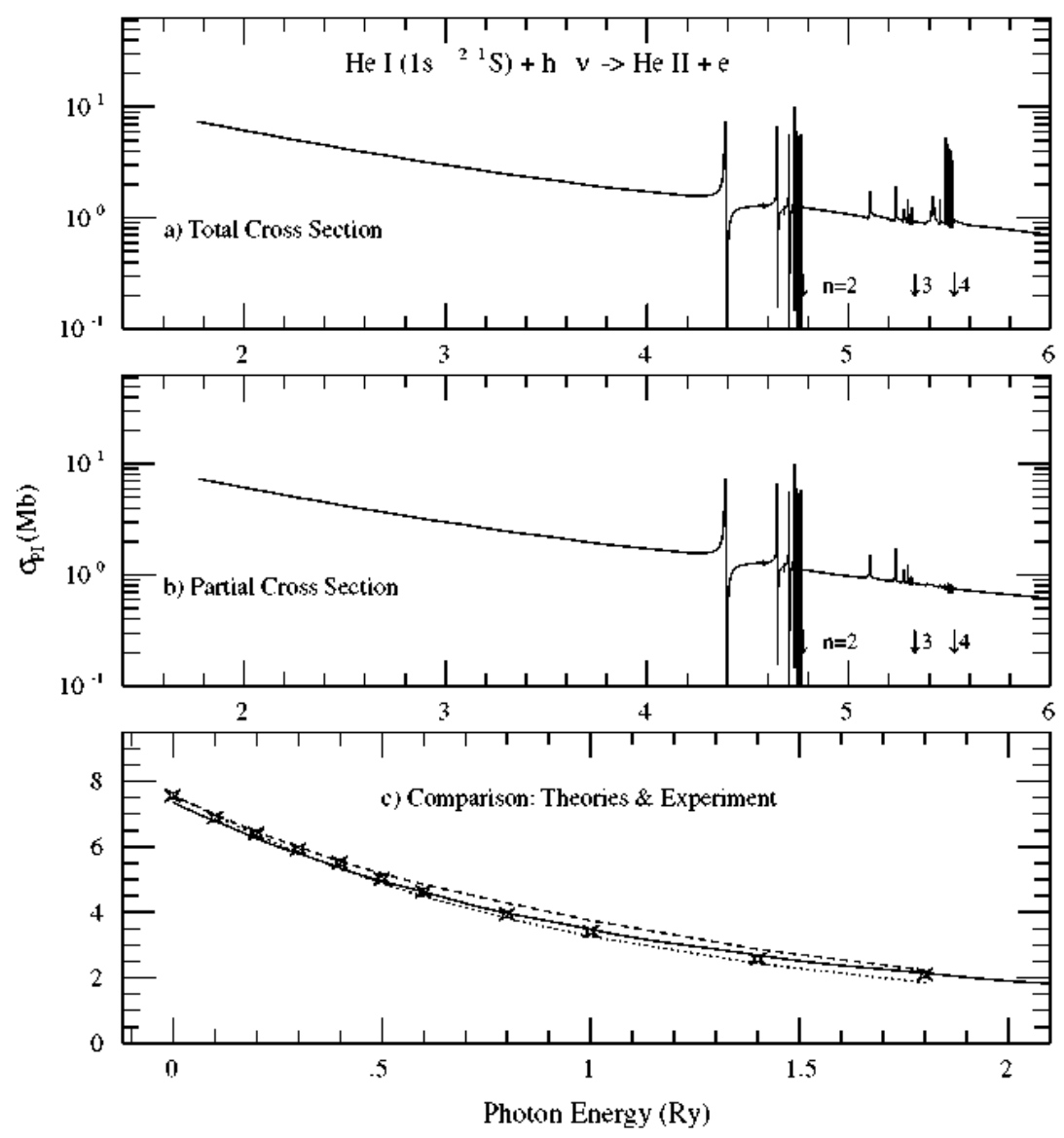

Fig. 1. Photoionization cross sections $\sigma_{\mathrm{PI}}$ of the ground state $1 \mathrm{~s}^{2}{ }^{1} \mathrm{~S}$ : (a) total for leaving core in the ground and various excited states and (b) partial for leaving the core in the ground state, (c) comparison between experiment and theories. In (a) and (b), the excited $n=2,3$ and 4 thresholds of the core are pointed by arrows where various Rydberg series of resonances are converging. The total and partial $\sigma_{\mathrm{PI}}$ have the same features up to $n=2$ beyond which the background and strengths of resonances of the partial cross section decrease because of no contributions from the channels of ionization with excited core thresholds. (c) Comparison of the present cross section (solid) with experiment (asterisk, Samson, 1976) and theories of hyperspherical coordinate method (dot, Miller and Starace, 1980) and random-phase approximation (dash, Wendin, 1971).

wave functions from atomic structure calculations which are the input to initiate the R-matrix calculations. The code SUPERSTRUCTURE (Eissner et al., 1974) was used to generate one-electron orbital wave functions of core He II. The wave function expansion of He I included 10 states of the core as given in Table 1 . These target terms along with the wave functions of the interacting electron with partial waves $l \leq 9$ constituted the first term of He I wave function. Each partial wave has a R-matrix basis set 50 terms. The second term of the He I wave function 
expansion included all possible 2-electron configurations with orbital occupancies ranging as quoted within parentheses of $1 s(0-2), 2 s(0-2), 2 p(0-2), 3 s(0-2), 3 p(0-2), 3 d(0-2), 4 s(0-1), 4 p(0-1)$, $4 d(0-1), 4 f(0-1)$.

The bound states are computed through STGB where the energy eigenvalues are obtained by searching the poles in the Hamiltonian. The identifications of the states were checked through the quantum defects. Photoionization cross sections were obtained from STGBF of the R-matrix codes where the resonances in photoionization cross sections were delineated up to the highest core threshold of $n=4$. $\sigma_{P I}$ at higher photoelectron energies were extrapolated as explained in Nahar and Pradhan, 1994 and all atomic data were processed by the code ELEVID (Nahar and Pradhan, 1992b).

Recombination rate coefficients for all bound states with $n \leq 10$ are obtained from code RECOMB (Nahar and Pradhan, 1994) and are added together for the total. The contributions of high- $n$ states below the target thresholds are obtained from the resonance averaged DR collision strength $\Omega(D R)$ using code STGFDR (Nahar and Pradhan, 1994). $\Omega(D R)$ was calculated using the radiative decay rates or $A$-values for core excitations $1 \mathrm{~s}-2 \mathrm{p}(A=1.00 \mathrm{E}+10 / \mathrm{s}), 1 \mathrm{~s}-3 \mathrm{p}(A=$ $2.68 \mathrm{E}+09 / \mathrm{s})$ and $1 \mathrm{~s}-4 \mathrm{p}(A=1.09 \mathrm{E}+09 / \mathrm{s})$. These values were obtained from the atomic structure calculations of the core using code SUPERSTRUCTURE (Eissner et al., 1974). The contributions from all $n \leq \infty$ were added for the total unified $\sigma_{\mathrm{RC}}(\mathrm{E}), \alpha_{\mathrm{R}}(\mathrm{E})$ and $\alpha_{R}(T)$ were obtained using programs RECXSLS (Nahar, 2004) and PRCOMG (Nahar and Pradhan, 1994), respectively.

\section{Results and discussions}

Self-consistent results are presented for the inverse processes of photoionization and electron-ion recombination of neutral helium He I using the unified method for the total recombination. The aim is to get overall and self-consistent features and atomic data for these processes for astrophysical applications.

Following subsections discuss energies, photoionization cross sections and recombination rates in separately.

\subsection{LS term energies}

A total of 99 bound states of He I of singlet and triplet symmetries have been obtained. These energies will be available electronically. The calculated energies are compared in Table 2 with the LS term energies obtained from statistical averaging of fine structure levels (Drake and Martin, 1998) available at the NIST website (NIST). Very good agreement is found between two sets, mostly in less than $1 \%$, except for the ground $1 \mathrm{~s}^{2}\left({ }^{1} \mathrm{~S}\right)$ state for which the present value has $1.85 \%$ and for $1 \mathrm{~s} 2 \mathrm{~s}\left({ }^{1} \mathrm{~S}\right)$ state has $1 \%$ differences, 


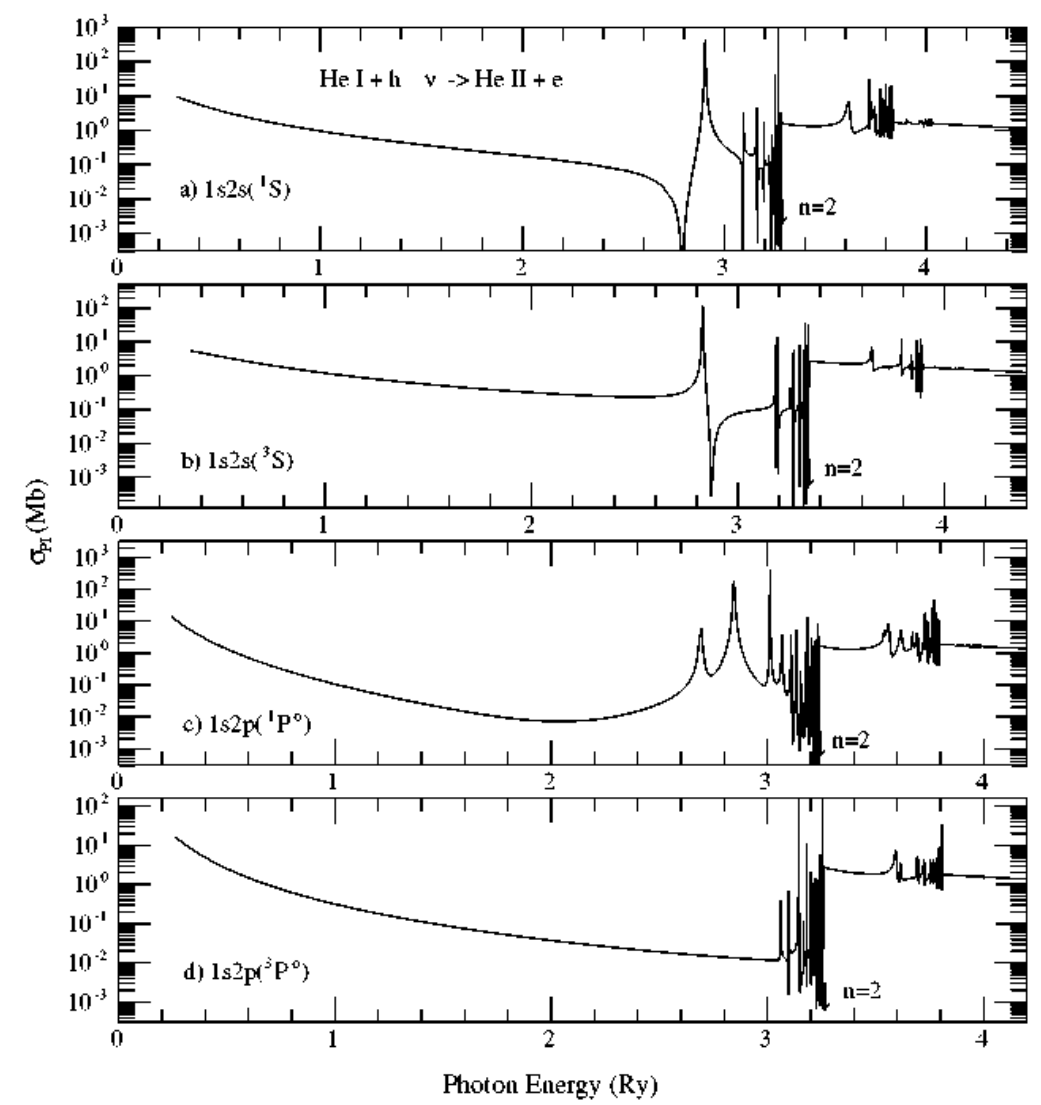

Fig. 2. Total photoionization cross sections $\sigma_{\mathrm{PI}}$ of the four excited $n=2$ states of He I. Three of these are relevant to the diagnostic $\mathrm{K}-\alpha$ lines of He-like ions. Each state shows considerable enhancement in the background cross sections at the photon energy corresponding to $n=2$ core threshold as 1 s-electron is ionized leaving the 21 electron in the residual ion.

respectively. All states available at NIST compilation have been found in the calculated set except four of the very high lying $(n=10)$ states. A future computation with better optimized wave functions may result in finding these states.

\subsection{Total and partial photoionization cross sections}

The present work reports photoionization cross sections $\sigma_{P I}$ for both the total and partial photoionization of 99 bound states of $n \leq 10$ of He I. The total photoionization cross sections $\sigma_{P I}(n L S)$ include contributions from all channels for ionization in to various excited core states and partial cross sections for ionization in to the core ground state. While total cross sections are needed for various astrophysical applications, such as opacity calculations, modeling of spectra, the partial cross sections are needed for recombination rates, cascade coefficients, populations of levels.

Fig. 1 presents the (a) total and (b) partial photoionization cross sections $\sigma_{P I}$ of the ground state $1 \mathrm{~s}^{2}{ }^{1} \mathrm{~S}$ of $\mathrm{He} \mathrm{I}$, and (c) comparison with existing experimental and other theoretical values. The ground state photoionization cross section shows smooth decay of the background cross section before the appearance of resonances due to Rydberg series of autoionizing states belonging to core excitation thresholds of $n=2$. The arrows in the figure point to the energy positions for core excitations to $n=2,3$ and 4 states. The most dominating resonances are due to Rydberg series belonging to $n=2$ states of core He II. The difference between the total and partial cross sections 
are in the lower background and weaker resonances in the latter which does not include contributions of channels of ionization with excited core states.

Fig. 1c presents comparison of the present cross section of the ground state with the measured values by Samson (1976) and two other calculations (Wendin, 1970, 1971; Miller and Starace, 1980) given in terms of photoelectron energy. Comparison shows that present close coupling $\sigma_{P I}$ (solid) agree with all measured points (asterisks, Samson, 1976). Only one point of the present cross section, $7.35 \mathrm{Mb}$, at the ionization threshold is below the measured value, but it is still within the uncertainty of the measurement $7.56( \pm 0.23)$. On the other hand $\sigma_{P I}$ curve from the hyperspherical coordinate method (dot, Miller and Starace, 1980) is slightly lower and from the random-phase approximation (dash, Wendin, 1970, 1971) is slightly higher than the measured curve.

Compared to relatively smooth background of the ground state, the excited states of $\mathrm{He} \mathrm{I}$ show more resonant features and enhancements in the background photoionization cross sections. Fig. 2 presents $\sigma_{P I}$ of the first four excited states (a) $1 \mathrm{~s} 2 \mathrm{~s}\left({ }^{1} \mathrm{~S}\right)$, (b) $1 \mathrm{~s} 2 \mathrm{~s}\left({ }^{3} \mathrm{~S}\right)$, (c) $1 \mathrm{~s} 2 \mathrm{p}\left({ }^{1} \mathrm{P}^{\mathrm{o}}\right)$, and $1 \mathrm{~s} 2 \mathrm{p}\left({ }^{3} \mathrm{P}^{\mathrm{o}}\right)$ of He I. These states show smooth background until the appearances of $L L^{\prime}, L M$, etc. resonances which converge on to $n=2$ thresholds with considerable enhancements in the background right at the $n=2$ excitation threshold (shown by arrow). The reason can be explained by the resonant ionization of the 1 s-electron leaving the $2 p$ electron in the residual ion. For He-like ions, the last three states ${ }^{3} S,{ }^{1} P^{o},{ }^{3} P^{o}$, correspond to diagnostic lines $\mathrm{w}, \mathrm{x}, \mathrm{y}$, and $z$. Although for helium these lines lie close together, for highly charged He-like ions, they are easily distinguishable.

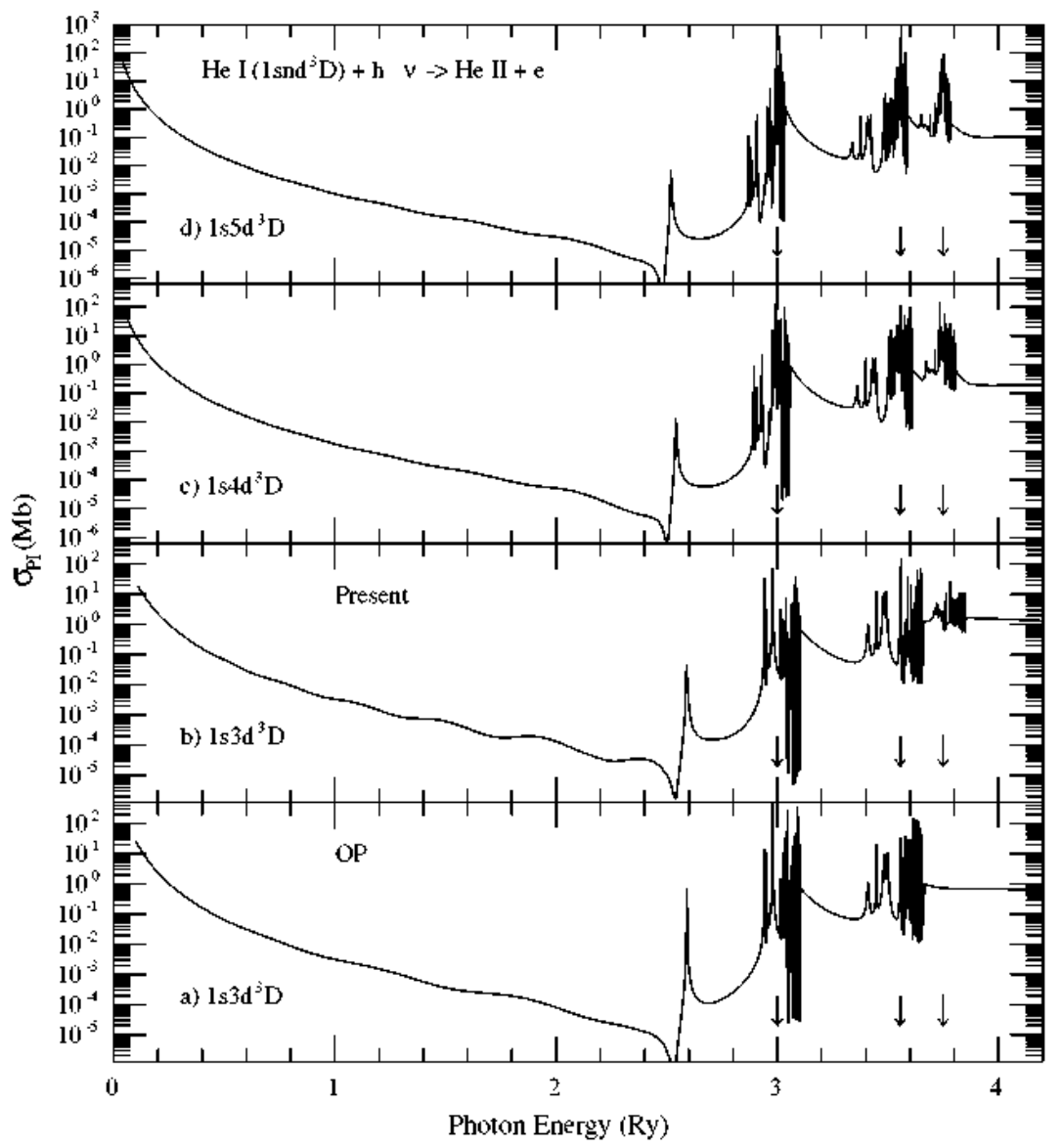


Fig. 3. Total photoionization cross sections, $\sigma_{\mathrm{P}}$, of excited Rydberg series of states $1 \operatorname{snd}\left({ }^{3} D\right)$, with $3 \leq n \leq 5$, of He I. The prominent PEC resonances (pointed by arrows) at photon energies 3.0 Ry (2p), $3.556 \mathrm{Ry}(3 \mathrm{p})$ and $3.75 \mathrm{Ry}(4 \mathrm{p})$ are formed due to dipole allowed $(1 \mathrm{~s}-n p)$ transitions by the core ground state. The resonances become prominent with higher $n$. The lowest panel (a) presents $\sigma_{P I}$ of $1 \mathrm{~s} 3 \mathrm{~d}\left({ }^{3} \mathrm{D}\right)$ obtained by Fernley et al. (1987) under the OP and shows similarities in features with the present $\sigma_{P I}$ in (b) except for the last $n=4$ resonance complex which is missing in the former $\sigma_{P I}$ 


\begin{tabular}{|c|c|c|c|c|c|c|c|}
\hline \multirow{3}{*}{$\begin{array}{l}\log _{10} \mathrm{~T} \\
\mathrm{BE}(\mathrm{Ry})=\end{array}$} & \multicolumn{7}{|c|}{$\alpha_{\mathrm{R}}(\mathrm{nSL} \pi)\left(\mathrm{cm}^{3} / \mathrm{s}\right)$} \\
\hline & $1 \mathrm{~s}^{2} \mathrm{~S}: 1$ & $1 \mathrm{~s} 2 \mathrm{~s}{ }^{1} \mathrm{~S}: 2$ & $1 \mathrm{~s} 3 \mathrm{~s}^{1} \mathrm{~S}: 3$ & $1 \mathrm{~s} 2 \mathrm{~s}{ }^{3} \mathrm{~S}: 1$ & $1 \mathrm{~s} 3 \mathrm{~s}^{3} \mathrm{~S}: 2$ & $1 \mathrm{~s} 2 \mathrm{p}{ }^{1} P^{o}: 1$ & $1 \mathrm{~s} 2 \mathrm{p}^{3} P^{\mathrm{o}}: 1$ \\
\hline & $-1.77 \mathrm{E}+00$ & $-2.89 \mathrm{E}-01$ & $-1.22 \mathrm{E}-01$ & $-3.50 \mathrm{E}-01$ & $-1.37 \mathrm{E}-01$ & $-2.47 \mathrm{E}-01$ & $-2.66 \mathrm{E}-01$ \\
\hline 1.0 & $4.78 \mathrm{E}-12$ & $1.64 \mathrm{E}-13$ & $4.52 \mathrm{E}-14$ & $4.09 \mathrm{E}-13$ & $9.06 \mathrm{E}-14$ & $5.05 \mathrm{E}-13$ & $2.08 \mathrm{E}-12$ \\
\hline 1.1 & $4.26 \mathrm{E}-12$ & $1.46 \mathrm{E}-13$ & $4.03 \mathrm{E}-14$ & $3.65 \mathrm{E}-13$ & $8.08 \mathrm{E}-14$ & $4.50 \mathrm{E}-13$ & $1.86 \mathrm{E}-12$ \\
\hline 1.2 & $3.80 \mathrm{E}-12$ & $1.30 \mathrm{E}-13$ & $3.59 \mathrm{E}-14$ & $3.25 \mathrm{E}-13$ & $7.20 \mathrm{E}-14$ & $4.01 \mathrm{E}-13$ & $1.66 \mathrm{E}-12$ \\
\hline 1.3 & $3.38 \mathrm{E}-12$ & $1.16 \mathrm{E}-13$ & $3.20 \mathrm{E}-14$ & $2.90 \mathrm{E}-13$ & $6.42 \mathrm{E}-14$ & $3.58 \mathrm{E}-13$ & $1.48 \mathrm{E}-12$ \\
\hline 1.4 & $3.02 \mathrm{E}-12$ & $1.03 \mathrm{E}-13$ & $2.86 \mathrm{E}-14$ & $2.58 \mathrm{E}-13$ & $5.72 \mathrm{E}-14$ & $3.19 \mathrm{E}-13$ & $1.32 \mathrm{E}-12$ \\
\hline 1.5 & $2.69 \mathrm{E}-12$ & $9.20 \mathrm{E}-14$ & $2.55 \mathrm{E}-14$ & $2.30 \mathrm{E}-13$ & $5.10 \mathrm{E}-14$ & $2.84 \mathrm{E}-13$ & $1.17 \mathrm{E}-12$ \\
\hline 1.6 & $2.40 \mathrm{E}-12$ & $8.20 \mathrm{E}-14$ & $2.27 \mathrm{E}-14$ & $2.05 \mathrm{E}-13$ & $4.55 \mathrm{E}-14$ & $2.53 \mathrm{E}-13$ & $1.04 \mathrm{E}-12$ \\
\hline 1.7 & $2.14 \mathrm{E}-12$ & $7.31 \mathrm{E}-14$ & $2.02 \mathrm{E}-14$ & $1.83 \mathrm{E}-13$ & $4.06 \mathrm{E}-14$ & $2.25 \mathrm{E}-13$ & $9.31 \mathrm{E}-13$ \\
\hline 1.8 & $1.90 \mathrm{E}-12$ & $6.52 \mathrm{E}-14$ & $1.80 \mathrm{E}-14$ & $1.63 \mathrm{E}-13$ & $3.62 \mathrm{E}-14$ & $2.01 \mathrm{E}-13$ & $8.29 \mathrm{E}-13$ \\
\hline 1.9 & $1.70 \mathrm{E}-12$ & $5.81 \mathrm{E}-14$ & $1.61 \mathrm{E}-14$ & $1.45 \mathrm{E}-13$ & $3.23 \mathrm{E}-14$ & $1.79 \mathrm{E}-13$ & 7.39E-13 \\
\hline 2.0 & $1.51 \mathrm{E}-12$ & $5.18 \mathrm{E}-14$ & $1.43 \mathrm{E}-14$ & $1.30 \mathrm{E}-13$ & $2.88 \mathrm{E}-14$ & $1.59 \mathrm{E}-13$ & $6.58 \mathrm{E}-13$ \\
\hline 2.1 & $1.35 \mathrm{E}-12$ & $4.62 \mathrm{E}-14$ & $1.28 \mathrm{E}-14$ & $1.16 \mathrm{E}-13$ & $2.57 \mathrm{E}-14$ & $1.42 \mathrm{E}-13$ & $5.86 \mathrm{E}-13$ \\
\hline 2.2 & $1.20 \mathrm{E}-12$ & $4.11 \mathrm{E}-14$ & $1.14 \mathrm{E}-14$ & $1.03 \mathrm{E}-13$ & $2.29 \mathrm{E}-14$ & $1.26 \mathrm{E}-13$ & $5.22 \mathrm{E}-13$ \\
\hline 2.3 & $1.07 \mathrm{E}-12$ & $3.67 \mathrm{E}-14$ & $1.02 \mathrm{E}-14$ & $9.20 \mathrm{E}-14$ & $2.05 \mathrm{E}-14$ & $1.12 \mathrm{E}-13$ & $4.65 \mathrm{E}-13$ \\
\hline 2.4 & $9.54 \mathrm{E}-13$ & $3.27 \mathrm{E}-14$ & $9.07 \mathrm{E}-15$ & $8.20 \mathrm{E}-14$ & $1.83 \mathrm{E}-14$ & $1.00 \mathrm{E}-13$ & $4.14 \mathrm{E}-13$ \\
\hline 2.5 & $8.50 \mathrm{E}-13$ & $2.92 \mathrm{E}-14$ & $8.10 \mathrm{E}-15$ & 7.32E-14 & $1.63 \mathrm{E}-14$ & $8.91 \mathrm{E}-14$ & $3.69 \mathrm{E}-13$ \\
\hline 2.6 & $7.58 \mathrm{E}-13$ & $2.60 \mathrm{E}-14$ & $7.23 \mathrm{E}-15$ & $6.54 \mathrm{E}-14$ & $1.46 \mathrm{E}-14$ & 7.92E-14 & $3.28 \mathrm{E}-13$ \\
\hline 2.7 & $6.76 \mathrm{E}-13$ & $2.32 \mathrm{E}-14$ & $6.45 \mathrm{E}-15$ & $5.84 \mathrm{E}-14$ & $1.31 \mathrm{E}-14$ & 7.04E-14 & $2.92 \mathrm{E}-13$ \\
\hline 2.8 & $6.02 \mathrm{E}-13$ & $2.07 \mathrm{E}-14$ & 5.77E-15 & $5.22 \mathrm{E}-14$ & $1.17 \mathrm{E}-14$ & $6.25 \mathrm{E}-14$ & $2.60 \mathrm{E}-13$ \\
\hline 2.9 & $5.37 \mathrm{E}-13$ & $1.85 \mathrm{E}-14$ & $5.16 \mathrm{E}-15$ & $4.67 \mathrm{E}-14$ & $1.05 \mathrm{E}-14$ & $5.55 \mathrm{E}-14$ & $2.31 \mathrm{E}-13$ \\
\hline 3.0 & $4.79 \mathrm{E}-13$ & $1.65 \mathrm{E}-14$ & $4.62 \mathrm{E}-15$ & $4.17 \mathrm{E}-14$ & $9.45 \mathrm{E}-15$ & $4.92 \mathrm{E}-14$ & $2.05 \mathrm{E}-13$ \\
\hline 3.1 & $4.27 \mathrm{E}-13$ & $1.48 \mathrm{E}-14$ & 4.13E-15 & $3.74 \mathrm{E}-14$ & $8.50 \mathrm{E}-15$ & 4.35E-14 & $1.82 \mathrm{E}-13$ \\
\hline
\end{tabular}




\begin{tabular}{|c|c|c|c|c|c|c|c|}
\hline 3.2 & $3.81 \mathrm{E}-13$ & $1.32 \mathrm{E}-14$ & $3.71 \mathrm{E}-15$ & 3.35E-14 & 7.67E-15 & $3.84 \mathrm{E}-14$ & $1.61 \mathrm{E}-13$ \\
\hline 3.3 & $3.40 \mathrm{E}-13$ & $1.18 \mathrm{E}-14$ & 3.33E-15 & 3.01E-14 & $6.94 \mathrm{E}-15$ & $3.39 \mathrm{E}-14$ & $1.42 \mathrm{E}-13$ \\
\hline 3.4 & $3.03 \mathrm{E}-13$ & $1.06 \mathrm{E}-14$ & $2.99 \mathrm{E}-15$ & $2.71 \mathrm{E}-14$ & $6.30 \mathrm{E}-15$ & $2.98 \mathrm{E}-14$ & $1.26 \mathrm{E}-13$ \\
\hline 3.5 & $2.70 \mathrm{E}-13$ & $9.48 \mathrm{E}-15$ & $2.69 \mathrm{E}-15$ & 2.44E-14 & $5.73 \mathrm{E}-15$ & 2.62E-14 & $1.11 \mathrm{E}-13$ \\
\hline 3.6 & $2.41 \mathrm{E}-13$ & $8.50 \mathrm{E}-15$ & 2.43E-15 & $2.21 \mathrm{E}-14$ & $5.23 \mathrm{E}-15$ & $2.29 \mathrm{E}-14$ & $9.75 \mathrm{E}-14$ \\
\hline 3.7 & $2.15 \mathrm{E}-13$ & $7.63 \mathrm{E}-15$ & $2.19 \mathrm{E}-15$ & $2.00 \mathrm{E}-14$ & $4.78 \mathrm{E}-15$ & $1.99 \mathrm{E}-14$ & $8.55 \mathrm{E}-14$ \\
\hline 3.8 & $1.92 \mathrm{E}-13$ & $6.86 \mathrm{E}-15$ & $1.98 \mathrm{E}-15$ & $1.81 \mathrm{E}-14$ & $4.39 \mathrm{E}-15$ & $1.72 \mathrm{E}-14$ & 7.47E-14 \\
\hline 3.9 & $1.72 \mathrm{E}-13$ & $6.18 \mathrm{E}-15$ & $1.79 \mathrm{E}-15$ & $1.65 \mathrm{E}-14$ & $4.04 \mathrm{E}-15$ & $1.48 \mathrm{E}-14$ & $6.50 \mathrm{E}-14$ \\
\hline 4.0 & $1.54 \mathrm{E}-13$ & $5.57 \mathrm{E}-15$ & $1.62 \mathrm{E}-15$ & $1.51 \mathrm{E}-14$ & $3.73 \mathrm{E}-15$ & $1.27 \mathrm{E}-14$ & 5.63E-14 \\
\hline 4.1 & $1.38 \mathrm{E}-13$ & $5.02 \mathrm{E}-15$ & $1.46 \mathrm{E}-15$ & $1.38 \mathrm{E}-14$ & $3.46 \mathrm{E}-15$ & $1.08 \mathrm{E}-14$ & $4.85 \mathrm{E}-14$ \\
\hline 4.2 & $1.23 \mathrm{E}-13$ & $4.53 \mathrm{E}-15$ & $1.32 \mathrm{E}-15$ & $1.27 \mathrm{E}-14$ & $3.20 \mathrm{E}-15$ & $9.12 \mathrm{E}-15$ & 4.16E-14 \\
\hline 4.3 & $1.10 \mathrm{E}-13$ & 4.08E-15 & $1.19 \mathrm{E}-15$ & $1.17 \mathrm{E}-14$ & $2.97 \mathrm{E}-15$ & 7.63E-15 & $3.54 \mathrm{E}-14$ \\
\hline 4.4 & $9.91 \mathrm{E}-14$ & $3.68 \mathrm{E}-15$ & $1.08 \mathrm{E}-15$ & $1.08 \mathrm{E}-14$ & $2.76 \mathrm{E}-15$ & $6.32 \mathrm{E}-15$ & $3.00 \mathrm{E}-14$ \\
\hline 4.5 & $8.90 \mathrm{E}-14$ & $3.31 \mathrm{E}-15$ & $9.69 \mathrm{E}-16$ & $9.98 \mathrm{E}-15$ & $2.56 \mathrm{E}-15$ & $5.20 \mathrm{E}-15$ & $2.52 \mathrm{E}-14$ \\
\hline 4.6 & $8.00 \mathrm{E}-14$ & $2.99 \mathrm{E}-15$ & $8.71 \mathrm{E}-16$ & $9.23 \mathrm{E}-15$ & $2.39 \mathrm{E}-15$ & 4.25E-15 & $2.10 \mathrm{E}-14$ \\
\hline 4.7 & 7.19E-14 & $2.72 \mathrm{E}-15$ & 7.94E-16 & $8.60 \mathrm{E}-15$ & $2.28 \mathrm{E}-15$ & 3.57E-15 & $1.74 \mathrm{E}-14$ \\
\hline 4.8 & $6.47 \mathrm{E}-14$ & $2.61 \mathrm{E}-15$ & 7.71E-16 & $8.17 \mathrm{E}-15$ & $2.41 \mathrm{E}-15$ & 3.37E-15 & $1.44 \mathrm{E}-14$ \\
\hline 4.9 & 5.83E-14 & $2.75 \mathrm{E}-15$ & 8.61E-16 & $8.06 \mathrm{E}-15$ & 3.03E-15 & 3.96E-15 & $1.20 \mathrm{E}-14$ \\
\hline 5.0 & $5.25 \mathrm{E}-14$ & $3.21 \mathrm{E}-15$ & $1.11 \mathrm{E}-15$ & $8.26 \mathrm{E}-15$ & $4.35 \mathrm{E}-15$ & $5.48 \mathrm{E}-15$ & $1.02 \mathrm{E}-14$ \\
\hline 5.1 & $4.72 \mathrm{E}-14$ & 3.92E-15 & $1.50 \mathrm{E}-15$ & $8.64 \mathrm{E}-15$ & $6.24 \mathrm{E}-15$ & 7.66E-15 & 8.97E-15 \\
\hline 5.2 & $4.25 \mathrm{E}-14$ & $4.66 \mathrm{E}-15$ & $1.94 \mathrm{E}-15$ & 8.97E-15 & $8.30 \mathrm{E}-15$ & $9.92 \mathrm{E}-15$ & $8.13 \mathrm{E}-15$ \\
\hline 5.3 & $3.82 \mathrm{E}-14$ & $5.21 \mathrm{E}-15$ & $2.31 \mathrm{E}-15$ & $9.05 \mathrm{E}-15$ & $9.98 \mathrm{E}-15$ & $1.16 \mathrm{E}-14$ & 7.47E-15 \\
\hline 5.4 & $3.44 \mathrm{E}-14$ & $5.44 \mathrm{E}-15$ & $2.52 \mathrm{E}-15$ & $8.78 \mathrm{E}-15$ & $1.09 \mathrm{E}-14$ & $1.25 \mathrm{E}-14$ & $6.81 \mathrm{E}-15$ \\
\hline 5.5 & $3.00 \mathrm{E}-14$ & $5.30 \mathrm{E}-15$ & $2.54 \mathrm{E}-15$ & $8.10 \mathrm{E}-15$ & $1.10 \mathrm{E}-14$ & $1.23 \mathrm{E}-14$ & 6.07E-15 \\
\hline 5.6 & $2.65 \mathrm{E}-14$ & $4.89 \mathrm{E}-15$ & $2.39 \mathrm{E}-15$ & 7.23E-15 & $1.03 \mathrm{E}-14$ & $1.14 \mathrm{E}-14$ & $5.26 \mathrm{E}-15$ \\
\hline 5.7 & $2.28 \mathrm{E}-14$ & $4.30 \mathrm{E}-15$ & 2.13E-15 & $6.20 \mathrm{E}-15$ & $9.14 \mathrm{E}-15$ & $9.95 \mathrm{E}-15$ & $4.42 \mathrm{E}-15$ \\
\hline
\end{tabular}




\begin{tabular}{|c|c|c|c|c|c|c|c|}
\hline 5.8 & $1.96 \mathrm{E}-14$ & $3.65 \mathrm{E}-15$ & $1.83 \mathrm{E}-15$ & $5.20 \mathrm{E}-15$ & 7.77E-15 & $8.35 \mathrm{E}-15$ & 3.62E-15 \\
\hline 5.9 & $1.67 \mathrm{E}-14$ & $3.00 \mathrm{E}-15$ & $1.51 \mathrm{E}-15$ & $4.26 \mathrm{E}-15$ & $6.37 \mathrm{E}-15$ & $6.78 \mathrm{E}-15$ & $2.90 \mathrm{E}-15$ \\
\hline 6.0 & $1.38 \mathrm{E}-14$ & $2.40 \mathrm{E}-15$ & $1.21 \mathrm{E}-15$ & 3.41E-15 & $5.07 \mathrm{E}-15$ & $5.35 \mathrm{E}-15$ & $2.26 \mathrm{E}-15$ \\
\hline 6.1 & $1.12 \mathrm{E}-14$ & $1.88 \mathrm{E}-15$ & $9.43 \mathrm{E}-16$ & $2.68 \mathrm{E}-15$ & 3.94E-15 & $4.13 \mathrm{E}-15$ & $1.74 \mathrm{E}-15$ \\
\hline 6.2 & $9.10 \mathrm{E}-15$ & $1.45 \mathrm{E}-15$ & $7.25 \mathrm{E}-16$ & $2.10 \mathrm{E}-15$ & $3.01 \mathrm{E}-15$ & $3.14 \mathrm{E}-15$ & $1.32 \mathrm{E}-15$ \\
\hline 6.3 & $7.20 \mathrm{E}-15$ & $1.11 \mathrm{E}-15$ & $5.49 \mathrm{E}-16$ & $1.62 \mathrm{E}-15$ & $2.26 \mathrm{E}-15$ & $2.35 \mathrm{E}-15$ & $9.85 \mathrm{E}-16$ \\
\hline 6.4 & $5.69 \mathrm{E}-15$ & 8.34E-16 & 4.11E-16 & $1.24 \mathrm{E}-15$ & $1.69 \mathrm{E}-15$ & $1.75 \mathrm{E}-15$ & 7.32E-16 \\
\hline 6.5 & 4.29E-15 & $6.18 \mathrm{E}-16$ & 3.03E-16 & $9.31 \mathrm{E}-16$ & $1.24 \mathrm{E}-15$ & $1.28 \mathrm{E}-15$ & 5.35E-16 \\
\hline 6.6 & $3.30 \mathrm{E}-15$ & $4.58 \mathrm{E}-16$ & $2.22 \mathrm{E}-16$ & 7.07E-16 & $9.05 \mathrm{E}-16$ & $9.37 \mathrm{E}-16$ & $3.92 \mathrm{E}-16$ \\
\hline 6.7 & $2.53 \mathrm{E}-15$ & $3.37 \mathrm{E}-16$ & $1.62 \mathrm{E}-16$ & $5.35 \mathrm{E}-16$ & $6.58 \mathrm{E}-16$ & $6.82 \mathrm{E}-16$ & $2.86 \mathrm{E}-16$ \\
\hline 6.8 & $1.73 \mathrm{E}-15$ & $2.40 \mathrm{E}-16$ & $1.16 \mathrm{E}-16$ & 3.82E-16 & 4.71E-16 & $4.92 \mathrm{E}-16$ & 2.03E-16 \\
\hline 6.9 & $1.29 \mathrm{E}-15$ & $1.75 \mathrm{E}-16$ & $8.36 \mathrm{E}-17$ & $2.85 \mathrm{E}-16$ & $3.39 \mathrm{E}-16$ & $3.55 \mathrm{E}-16$ & $1.46 \mathrm{E}-16$ \\
\hline 7.0 & $9.58 \mathrm{E}-16$ & $1.27 \mathrm{E}-16$ & $6.01 \mathrm{E}-17$ & 2.13E-16 & $2.44 \mathrm{E}-16$ & $2.56 \mathrm{E}-16$ & $1.05 \mathrm{E}-16$ \\
\hline 7.1 & $6.93 \mathrm{E}-16$ & $9.12 \mathrm{E}-17$ & $4.30 \mathrm{E}-17$ & $1.57 \mathrm{E}-16$ & $1.74 \mathrm{E}-16$ & $1.84 \mathrm{E}-16$ & 7.54E-17 \\
\hline 7.2 & $5.08 \mathrm{E}-16$ & $6.57 \mathrm{E}-17$ & $3.08 \mathrm{E}-17$ & $1.16 \mathrm{E}-16$ & $1.24 \mathrm{E}-16$ & $1.32 \mathrm{E}-16$ & $5.41 \mathrm{E}-17$ \\
\hline 7.3 & $3.72 \mathrm{E}-16$ & $4.73 \mathrm{E}-17$ & $2.20 \mathrm{E}-17$ & $8.59 \mathrm{E}-17$ & $8.87 \mathrm{E}-17$ & $9.45 \mathrm{E}-17$ & $3.87 \mathrm{E}-17$ \\
\hline 7.4 & $2.72 \mathrm{E}-16$ & $3.40 \mathrm{E}-17$ & $1.57 \mathrm{E}-17$ & $6.35 \mathrm{E}-17$ & $6.33 \mathrm{E}-17$ & $6.77 \mathrm{E}-17$ & $2.77 \mathrm{E}-17$ \\
\hline 7.5 & $1.99 \mathrm{E}-16$ & $2.44 \mathrm{E}-17$ & $1.12 \mathrm{E}-17$ & 4.69E-17 & $4.51 \mathrm{E}-17$ & $4.84 \mathrm{E}-17$ & $1.98 \mathrm{E}-17$ \\
\hline 7.6 & $1.45 \mathrm{E}-16$ & $1.76 \mathrm{E}-17$ & 7.97E-18 & $3.46 \mathrm{E}-17$ & $3.21 \mathrm{E}-17$ & $3.47 \mathrm{E}-17$ & $1.42 \mathrm{E}-17$ \\
\hline 7.7 & $1.06 \mathrm{E}-16$ & $1.26 \mathrm{E}-17$ & $5.68 \mathrm{E}-18$ & $2.56 \mathrm{E}-17$ & $2.28 \mathrm{E}-17$ & $2.48 \mathrm{E}-17$ & $1.02 \mathrm{E}-17$ \\
\hline 7.8 & 7.77E-17 & $9.06 \mathrm{E}-18$ & 4.05E-18 & $1.89 \mathrm{E}-17$ & $1.62 \mathrm{E}-17$ & $1.77 \mathrm{E}-17$ & $7.28 \mathrm{E}-18$ \\
\hline 7.9 & $5.71 \mathrm{E}-17$ & $6.52 \mathrm{E}-18$ & $2.89 \mathrm{E}-18$ & $1.39 \mathrm{E}-17$ & $1.16 \mathrm{E}-17$ & $1.27 \mathrm{E}-17$ & $5.22 \mathrm{E}-18$ \\
\hline 8.0 & $4.21 \mathrm{E}-17$ & 4.69E-18 & $2.06 \mathrm{E}-18$ & 1.03E-17 & $8.24 \mathrm{E}-18$ & $9.06 \mathrm{E}-18$ & $3.74 \mathrm{E}-18$ \\
\hline 8.1 & $3.12 \mathrm{E}-17$ & $3.38 \mathrm{E}-18$ & $1.47 \mathrm{E}-18$ & 7.61E-18 & $5.87 \mathrm{E}-18$ & $6.48 \mathrm{E}-18$ & $2.69 \mathrm{E}-18$ \\
\hline 8.2 & $2.32 \mathrm{E}-17$ & $2.45 \mathrm{E}-18$ & $1.06 \mathrm{E}-18$ & $5.64 \mathrm{E}-18$ & $4.19 \mathrm{E}-18$ & 4.63E-18 & $1.94 \mathrm{E}-18$ \\
\hline 8.3 & $1.74 \mathrm{E}-17$ & $1.77 \mathrm{E}-18$ & 7.58E-19 & $4.19 \mathrm{E}-18$ & 2.99E-18 & 3.31E-18 & $1.40 \mathrm{E}-18$ \\
\hline
\end{tabular}




$\begin{array}{rlllllll}8.4 & 1.32 \mathrm{E}-17 & 1.29 \mathrm{E}-18 & 5.45 \mathrm{E}-19 & 3.12 \mathrm{E}-18 & 2.14 \mathrm{E}-18 & 2.37 \mathrm{E}-18 & 1.01 \mathrm{E}-18 \\ 8.5 & 1.00 \mathrm{E}-17 & 9.42 \mathrm{E}-19 & 3.94 \mathrm{E}-19 & 2.34 \mathrm{E}-18 & 1.53 \mathrm{E}-18 & 1.70 \mathrm{E}-18 & 7.36 \mathrm{E}-19 \\ 8.6 & 7.72 \mathrm{E}-18 & 6.91 \mathrm{E}-19 & 2.86 \mathrm{E}-19 & 1.76 \mathrm{E}-18 & 1.10 \mathrm{E}-18 & 1.22 \mathrm{E}-18 & 5.37 \mathrm{E}-19 \\ 8.7 & 6.01 \mathrm{E}-18 & 5.10 \mathrm{E}-19 & 2.08 \mathrm{E}-19 & 1.33 \mathrm{E}-18 & 7.96 \mathrm{E}-19 & 8.72 \mathrm{E}-19 & 3.95 \mathrm{E}-19 \\ 8.8 & 4.73 \mathrm{E}-18 & 3.79 \mathrm{E}-19 & 1.53 \mathrm{E}-19 & 1.01 \mathrm{E}-18 & 5.76 \mathrm{E}-19 & 6.27 \mathrm{E}-19 & 2.92 \mathrm{E}-19 \\ 8.9 & 3.76 \mathrm{E}-18 & 2.84 \mathrm{E}-19 & 1.13 \mathrm{E}-19 & 7.72 \mathrm{E}-19 & 4.19 \mathrm{E}-19 & 4.51 \mathrm{E}-19 & 2.17 \mathrm{E}-19 \\ 9.0 & 3.03 \mathrm{E}-18 & 2.15 \mathrm{E}-19 & 8.44 \mathrm{E}-20 & 5.96 \mathrm{E}-19 & 3.07 \mathrm{E}-19 & 3.25 \mathrm{E}-19 & 1.63 \mathrm{E}-19\end{array}$

Table 3 State-specific recombination rate coefficients $\alpha_{R}(n S L \pi)$ of the ground and several dominant excited states of He I. The number next to a state indicates its energy position in the symmetry. BE is the binding energy of the state. 
The PEC (photo-excitation-of-core) resonances in photoionization cross sections are distinct features of the excited states with one valence electron. These resonances are illustrated in Fig. 3 which presents $\sigma_{P I}$ of the excited states of He I, $1 \operatorname{snd}\left({ }^{3} \mathrm{D}\right)$ with $3 \leq n \leq 5$. These resonances appear at photon energies of excited core states for which the core ground state goes through a dipole allowed transition. Hence the PEC resonances are at $3 \mathrm{Ry}$ for $1 \mathrm{~s}-2 \mathrm{p}, 3.556 \mathrm{Ry}$ for $1 \mathrm{~s}-3 \mathrm{p}$, and $3.75 \mathrm{Ry}$ for $1 \mathrm{~s}-4 \mathrm{p}$ core excitations as pointed by arrows for all three states. (These excitation energies can be found in Table 1.) At these energies photons are absorbed for excitations while the outer electron remains inactive and ultimately lead to photionization via the outer electron when the core drops down to the ground state. PEC resonances contribute to photoionization and recombination rates at higher temperatures. PEC resonances become more distinct with higher $n$ as evident for $1 \mathrm{~s} 5 \mathrm{~d}$ state in the figure. The process is inverse to dielectronic recombination. PEC resonances were first explained and named by Seaton (1987b) in Yu and Seaton (1987).

Panels (a) and (b) of Fig. 3 compare $\sigma_{P I}$ from the earlier close coupling calculations by Fernley et al. (1987) under the OP and from the present work. The present $\sigma_{P I}$ agree very well with those by Fernley et al. (1987) available at the OP database, TOPbase (Cunto et al., 1993). The main difference is in the last $n=4$ resonance complex which is included in the present work, but not by Fernley et al. Hence the high energy cross sections by Fernley et al. often are somewhat lower than the present ones.

It may be noted that $\sigma_{P I}$ of $1 \mathrm{~s} 3 \mathrm{~d}\left({ }^{3} \mathrm{D}\right)$ state shows some oscillations in the energy region before the appearance of resonances. Although the magnitude of the cross section in the region of oscillations is very low to have any effect on applications, the

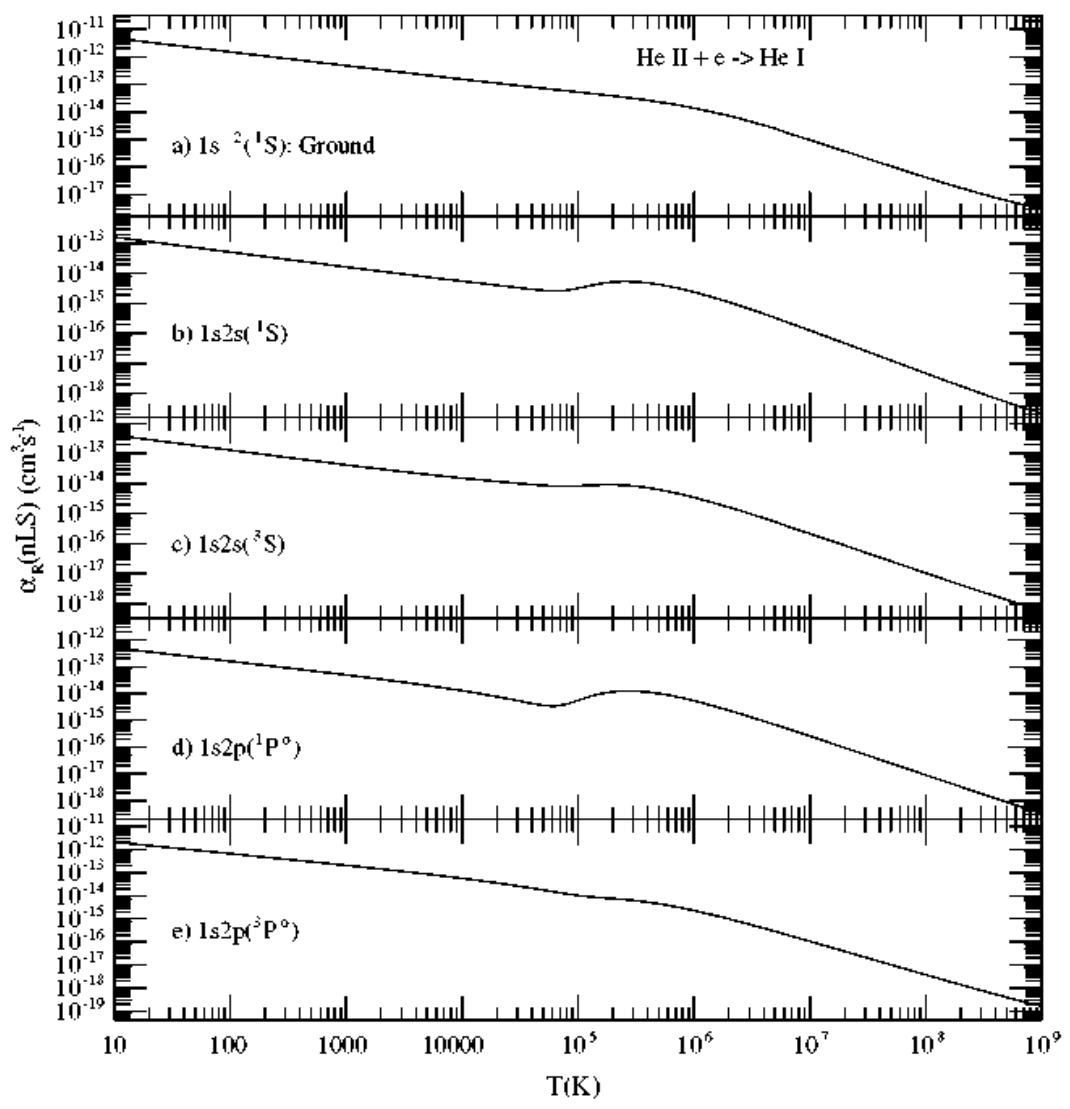

Fig. 4. Total $(R R+D R)$ state-specific recombination rate coefficients $\alpha_{R C}(n L S)$ of He I over a wide 
temperature range. The states are specified in each panel. Recombination rate of each state varies with temperature depending on the dominant resonant features in the state-specific photoionization. 


\begin{tabular}{|c|c|c|c|c|c|c|c|c|}
\hline \multirow{2}{*}{$\begin{array}{l}\log \mathrm{T} \\
\mathrm{K} \\
\end{array}$} & \multicolumn{2}{|c|}{$\alpha_{\mathrm{R}}\left(\mathrm{cm}^{3} \mathrm{~s}^{-1}\right)$} & \multirow{2}{*}{$\begin{array}{l}\log \mathrm{T} \\
\mathrm{K} \\
\end{array}$} & \multicolumn{2}{|c|}{$\alpha_{\mathrm{R}}\left(\mathrm{cm}^{3} \mathrm{~s}^{-1}\right)$} & \multirow{2}{*}{$\begin{array}{l}\log \mathrm{T} \\
\mathrm{K} \\
\end{array}$} & \multicolumn{2}{|l|}{$\underline{\alpha_{\mathrm{R}}\left(\mathrm{cm}^{3} \mathrm{~s}^{-1}\right)}$} \\
\hline & $\mathrm{He} \mathrm{I}$ & $\mathrm{He}$ II & & $\mathrm{He} \mathrm{I}$ & $\mathrm{He}$ II & & $\mathrm{He} \mathrm{I}$ & $\mathrm{He}$ II \\
\hline 1.0 & $3.43 \mathrm{E}-11$ & $1.55 \mathrm{E}-10$ & 3.7 & $6.84 \mathrm{E}-13$ & $3.46 \mathrm{E}-12$ & 6.4 & $3.00 \mathrm{E}-13$ & $2.42 \mathrm{E}-14$ \\
\hline 1.1 & $2.99 \mathrm{E}-11$ & $1.36 \mathrm{E}-10$ & 3.8 & $5.85 \mathrm{E}-13$ & $2.96 \mathrm{E}-12$ & 6.5 & $2.21 \mathrm{E}-13$ & $1.89 \mathrm{E}-14$ \\
\hline 1.2 & $2.60 \mathrm{E}-11$ & $1.19 \mathrm{E}-10$ & 3.9 & $5.00 \mathrm{E}-13$ & $2.55 \mathrm{E}-12$ & 6.6 & $1.62 \mathrm{E}-13$ & $1.47 \mathrm{E}-14$ \\
\hline 1.3 & $2.27 \mathrm{E}-11$ & $1.04 \mathrm{E}-10$ & 4.0 & $4.28 \mathrm{E}-13$ & $2.18 \mathrm{E}-12$ & 6.7 & $1.17 \mathrm{E}-13$ & $1.14 \mathrm{E}-14$ \\
\hline 1.4 & $1.98 \mathrm{E}-11$ & $9.08 \mathrm{E}-11$ & 4.1 & $3.66 \mathrm{E}-13$ & $1.87 \mathrm{E}-12$ & 6.8 & $8.47 \mathrm{E}-14$ & $8.68 \mathrm{E}-15$ \\
\hline 1.5 & $1.72 \mathrm{E}-11$ & $7.93 \mathrm{E}-11$ & 4.2 & $3.13 \mathrm{E}-13$ & $1.59 \mathrm{E}-12$ & 6.9 & $6.09 \mathrm{E}-14$ & $6.68 \mathrm{E}-15$ \\
\hline 1.6 & $1.50 \mathrm{E}-11$ & $6.92 \mathrm{E}-11$ & 4.3 & $2.68 \mathrm{E}-13$ & $1.36 \mathrm{E}-12$ & 7.0 & 4.37E-14 & $5.06 \mathrm{E}-15$ \\
\hline 1.7 & $1.30 \mathrm{E}-11$ & $6.04 \mathrm{E}-11$ & 4.4 & $2.29 \mathrm{E}-13$ & $1.16 \mathrm{E}-12$ & 7.1 & $3.13 \mathrm{E}-14$ & $3.82 \mathrm{E}-15$ \\
\hline 1.8 & $1.13 \mathrm{E}-11$ & $5.26 \mathrm{E}-11$ & 4.5 & $1.96 \mathrm{E}-13$ & $9.85 \mathrm{E}-13$ & 7.2 & $2.24 \mathrm{E}-14$ & $2.88 \mathrm{E}-15$ \\
\hline 1.9 & $9.84 \mathrm{E}-12$ & $4.60 \mathrm{E}-11$ & 4.6 & $1.70 \mathrm{E}-13$ & $8.36 \mathrm{E}-13$ & 7.3 & $1.59 \mathrm{E}-14$ & $2.15 \mathrm{E}-15$ \\
\hline 2.0 & $8.55 \mathrm{E}-12$ & $4.00 \mathrm{E}-11$ & 4.7 & $1.55 \mathrm{E}-13$ & $7.08 \mathrm{E}-13$ & 7.4 & $1.14 \mathrm{E}-14$ & $1.61 \mathrm{E}-15$ \\
\hline 2.1 & $7.42 \mathrm{E}-12$ & $3.48 \mathrm{E}-11$ & 4.8 & $1.75 \mathrm{E}-13$ & $5.97 \mathrm{E}-13$ & 7.5 & $8.09 \mathrm{E}-15$ & $1.19 \mathrm{E}-15$ \\
\hline 2.2 & $6.42 \mathrm{E}-12$ & $3.03 \mathrm{E}-11$ & 4.9 & $2.74 \mathrm{E}-13$ & $5.05 \mathrm{E}-13$ & 7.6 & $5.75 \mathrm{E}-15$ & $8.83 \mathrm{E}-16$ \\
\hline 2.3 & $5.57 \mathrm{E}-12$ & $2.64 \mathrm{E}-11$ & 5.0 & $4.91 \mathrm{E}-13$ & $4.24 \mathrm{E}-13$ & 7.7 & $4.09 \mathrm{E}-15$ & $6.51 \mathrm{E}-16$ \\
\hline 2.4 & $4.82 \mathrm{E}-12$ & $2.29 \mathrm{E}-11$ & 5.1 & $8.23 \mathrm{E}-13$ & $3.55 \mathrm{E}-13$ & 7.8 & $2.91 \mathrm{E}-15$ & $4.76 \mathrm{E}-16$ \\
\hline 2.5 & 4.17E-12 & $1.99 \mathrm{E}-11$ & 5.2 & $1.20 \mathrm{E}-12$ & $2.97 \mathrm{E}-13$ & 7.9 & $2.06 \mathrm{E}-15$ & $3.51 \mathrm{E}-16$ \\
\hline 2.6 & $3.60 \mathrm{E}-12$ & $1.73 \mathrm{E}-11$ & 5.3 & $1.54 \mathrm{E}-12$ & $2.47 \mathrm{E}-13$ & 8.0 & $1.47 \mathrm{E}-15$ & $2.55 \mathrm{E}-16$ \\
\hline 2.7 & $3.11 \mathrm{E}-12$ & $1.50 \mathrm{E}-11$ & 5.4 & $1.76 \mathrm{E}-12$ & $2.05 \mathrm{E}-13$ & 8.1 & $1.04 \mathrm{E}-15$ & $1.86 \mathrm{E}-16$ \\
\hline 2.8 & $2.68 \mathrm{E}-12$ & $1.30 \mathrm{E}-11$ & 5.5 & $1.82 \mathrm{E}-12$ & $1.70 \mathrm{E}-13$ & 8.2 & $7.40 \mathrm{E}-16$ & $1.35 \mathrm{E}-16$ \\
\hline 2.9 & $2.31 \mathrm{E}-12$ & $1.13 \mathrm{E}-11$ & 5.6 & $1.75 \mathrm{E}-12$ & $1.40 \mathrm{E}-13$ & 8.3 & $5.26 \mathrm{E}-16$ & $9.79 \mathrm{E}-17$ \\
\hline 3.0 & $1.99 \mathrm{E}-12$ & $9.73 \mathrm{E}-12$ & 5.7 & $1.58 \mathrm{E}-12$ & $1.14 \mathrm{E}-13$ & 8.4 & $3.74 \mathrm{E}-16$ & $7.08 \mathrm{E}-17$ \\
\hline 3.1 & $1.71 \mathrm{E}-12$ & $8.42 \mathrm{E}-12$ & 5.8 & $1.35 \mathrm{E}-12$ & $9.29 \mathrm{E}-14$ & 8.5 & $2.66 \mathrm{E}-16$ & $5.11 \mathrm{E}-17$ \\
\hline 3.2 & $1.47 \mathrm{E}-12$ & $7.28 \mathrm{E}-12$ & 5.9 & $1.12 \mathrm{E}-12$ & $7.56 \mathrm{E}-14$ & 8.6 & $1.89 \mathrm{E}-16$ & $3.68 \mathrm{E}-17$ \\
\hline
\end{tabular}




\begin{tabular}{lllllllll}
3.3 & $1.27 \mathrm{E}-12$ & $6.28 \mathrm{E}-12$ & 6.0 & $8.94 \mathrm{E}-13$ & $6.08 \mathrm{E}-14$ & 8.7 & $1.35 \mathrm{E}-16$ & $2.65 \mathrm{E}-17$ \\
3.4 & $1.09 \mathrm{E}-12$ & $5.42 \mathrm{E}-12$ & 6.1 & $6.98 \mathrm{E}-13$ & $4.87 \mathrm{E}-14$ & 8.8 & $9.61 \mathrm{E}-17$ & $1.89 \mathrm{E}-17$ \\
3.5 & $9.32 \mathrm{E}-13$ & $4.67 \mathrm{E}-12$ & 6.2 & $5.35 \mathrm{E}-13$ & $3.88 \mathrm{E}-14$ & 8.9 & $6.86 \mathrm{E}-17$ & $1.37 \mathrm{E}-17$ \\
3.6 & $7.98 \mathrm{E}-13$ & $4.02 \mathrm{E}-12$ & 6.3 & $4.03 \mathrm{E}-13$ & $3.07 \mathrm{E}-14$ & 9.0 & $4.91 \mathrm{E}-17$ & $9.75 \mathrm{E}-18$ \\
\hline
\end{tabular}

Table 4 Total recombination rate coefficients $\alpha_{R}(T)$ for $(\mathrm{e}+\mathrm{He}$ II $\rightarrow \mathrm{He} \mathrm{I})$ and $(\mathrm{e}+\mathrm{He} \mathrm{III} \rightarrow \mathrm{He}$ II). 


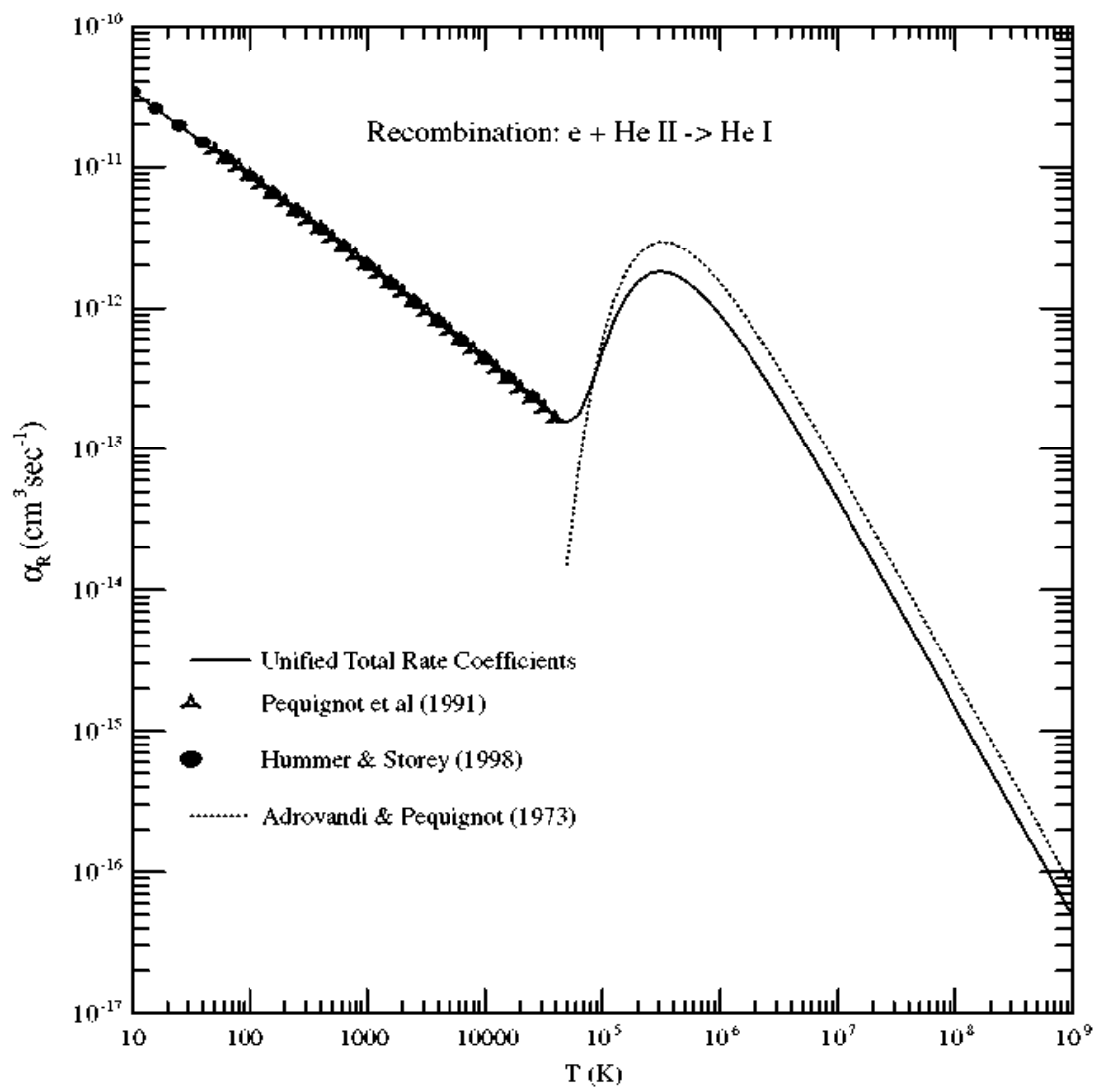

Fig. 5. Unified total $(R R+D R)$ electron-ion recombination rate coefficients $\alpha_{R}(T)$ of He I (solid curve). The present $\alpha_{R}(T)$ are compared with earlier RR rate coefficients by Pequignot et al. (1991) (triangles) and by Hummer and Storey (1998) (filled circles), and DR rate coefficients by (Aldrovandi and Pequignot, 1973) (dotted curve).

oscillatory nature indicates some numerical instability in the calculations. The effect of electron-electron interaction between the two electrons of He I continues over a large distance making the wave function sensitive to weaker part of the cross section. To improve the wave function, the R-matrix basis set was increased to 50 terms whereas for a typical atomic system, an expansion of 12 terms provide adequate convergence for the R-matrix boundary. Such increment introduces multiplicative dimensional problem for computations.

The present photoionization cross sections will be available electronically. The present data is more complete with 99 states than that for 43 states available at TOPbase. The Opacity Project data does not include partial photoionization cross sections as obtained in the present work.

\subsection{Total and state-specific recombination rate coefficients}

Total and state-specific recombination rate coefficients of the 99 bound states with $n \leq 10$ are reported. The state-specific recombination rate coefficients $\alpha_{R}(n L S)$ of the ground and seven lowest excited states of He I over a large temperature range are presented in Table 3 while rest are available electronically. The shapes of $\alpha_{R}(\mathrm{nLS})$ in to various individual states vary with temperature depending on the positions, strengths of the resonances and background features in the photoionization cross sections. Most of the states show one high temperature DR peak. Illustrative examples of $\alpha_{\mathrm{R}}(\mathrm{nLS})$ are given in Fig. 4 for the ground and 4 excited states of $n=2$ 
complex. These represent the total state-specific recombination rate coefficients for the states as they include both RR and DR.

Total unified recombination rate coefficients, $\alpha_{R}(T)$, for He I over a temperature range of 1 $\leq \log _{10} \mathrm{~T}(\mathrm{~K}) \leq 9$ are presented in Table 4 . The table also presents $\alpha_{\mathrm{R}}(\mathrm{T})$ for recombination of He III to hydrogen like He II obtained using the z-scale formula $\alpha_{\mathrm{R}}(\mathrm{z}, T)=\alpha_{\mathrm{R}}\left(\mathrm{H}, \mathrm{T} / \mathrm{z}^{2}\right)$, in terms of the recombination rate coefficient for neutral hydrogen (Nahar, 1996). The features of $\alpha_{R}(T)$ for He I are illustrated in Fig. 5. Radiative recombination dominates the low temperature region as seen in the smooth decay of $\alpha_{R}(T)$. In higher energy region where autoionizing resonances appear, dielectronic recombination dominates and forms a peak. The present results show that the DR peaks at temperature $\log _{10} \mathrm{~T}(\mathrm{~K})=5.5$ or $T=3.2 \times 10^{5} \mathrm{~K}$. Beyond the peak $\alpha_{\mathrm{R}}(\mathrm{T})$ falls smoothly.

The present total recombination rate coefficients $\alpha_{R}(T)$ are compared with published results in Fig. 5. Most of available rate coefficients are for the non-resonant part of the total rates and there is good agreement among the published results. The present $\alpha_{R}(T)$ are compared with RR rate coefficients by Pequignot et al. (1991) and the latest detailed work by Hummer and Storey (1998). The agreement is very good among the three calculations as they all fall on the same curve in the region where RR dominates. The DR coefficients for He I were obtained by Aldrovandi and Pequignot (1973) using the Burgess formula (1965). Their DR rate coefficient peaks around the same temperature as in the present case, but the rates are slightly higher than the present values. Burgess formula does not consider interference between RR and DR, and hence could be the possible reason for the difference.

Total recombination rate coefficient with photoelectron energy, $\alpha_{R}(E)$, is of considerable importance as it can reveal detailed resonant structures in the recombination spectrum and can be studied experimentally. Fig. 6 presents (a) the unified total recombination 

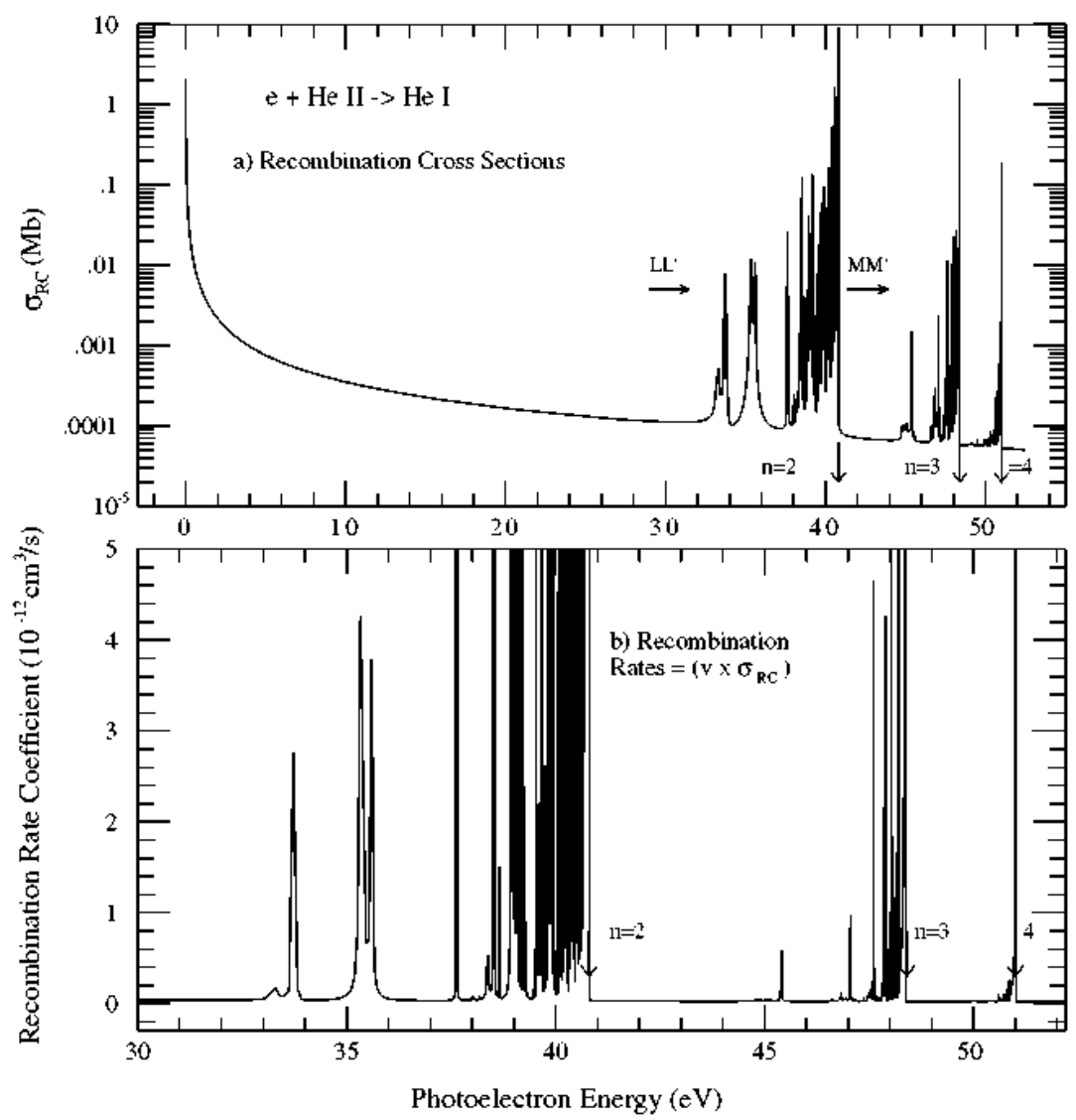

Fig. 6. Unified total (a) recombination cross section $\sigma_{R C}(E)$ and (b) recombination rate coefficients $\alpha_{\mathrm{RC}}(E)$ with photoelectron energy for (e $+\mathrm{He}$ II $\rightarrow \mathrm{He}$ I). Arrows in (a) and (b) point converging thresholds $n=2,3$, 4 where DR rate peaks and then drops to zero due to core excitation.

cross sections $\sigma_{R C}$ and (b) $\alpha_{\mathrm{R}}(\mathrm{E})$ at photoelectron energies for recombination to He I. The resonant part of $\alpha_{R}(E)$, as presented in Fig. 6b, can be observed in experimental set-ups. The figure shows resonance complexes belonging to $n=2,3$ and 4 states of core He II. They represent the capture of electron through DR. The resonances peak as the excitation threshold is approached and drop almost to zero as photon energy is used for excitation and electron is released. The recombination spectrum for recombination of He II to He I was measured by Tanabe et al. (1991) at the storage ring TARNII with electron cooler in Japan and by DeWitt et al. (1994) at the cooler storage ring CRYING in Stockholm. Both experiments found the structures shown in Fig. 6b. Tanabe et al. (1991) measured the broadened, due to convolution, resonant part in the energy range $\sim 38-41 \mathrm{eV}$. DeWitt et al. (1994) was able to have better resolution for more detailed structure of the same resonant region as well as the lowest $L L^{\prime}$ resonances belonging to 21 thresholds.

\section{Conclusion}

The inverse processes of photoionization and electron-ion recombination of $(\mathrm{h} v+\mathrm{He} \mathrm{I} \leftrightarrow \mathrm{e}$ $+\mathrm{He}$ II) are studied in detail by the self-consistent unified method. The results provide a complete view of the two processes of this element. A total of 99 bound states were obtained and they agree very well with the measured energies. Photoionization cross sections for all these bound states are presented for both total and partial ionization.

Study shows that the background photoionization of excited states are considerably 
enhanced by core excitations and existence of prominent PEC resonances. These contribute to the DR structure in high temperature. The DR introduces a peak in the total rate coefficients peak at $3.2 \times 10^{5} \mathrm{~K}$.

The present results for energies, photoionization cross section and recombination rates show good agreement with existing experimental measurements and other theoretical results. However, He I is an extremely important element in determining astronomical parameters and efforts are being made for highly accurate values for various atomic processes. The future plan aims such calculations with considerations of high order relativistic effects.

Additional Note: In addition to photoionization and electron-ion recombination data, oscillator strengths, line strengths, and radiative decay rates for all transitions calculated in the R-matrix calculations using the same bound state wave functions will be available electronically for consistent astrophysical models.

Files for photoionization cross sections, and total and state-specific recombination rates are available electronically from NORAD-Atomic-Data website at: www.astronomy.ohio-state.edu/nahar/ nahar_radiativeatomicdata.

\section{Acknowledgments}

This work was partially supported by the NASA Astronomy and Physics Research Analysis Program. The computational work was carried out on Cray machines at the Ohio Supercomputer Center in Columbus Ohio.

\section{References}

Aldrovandi, S.M.V., Pequignot, D., 1973. Astron. Astrophys. 25, 137.

Bell, R.H., Seaton, M.J., 1985. J. Phys. B 18, 1589.

Berrington, K.A., Burke, P.G., Butler, K., Seaton, M.J., Storey, P.J., Taylor, K.T., Yu, Y., 1987. J. Phys. B $20,6379$.

Burgess, A., 1965. Astrophys. J. 142, 1588.

Burgess, A., Seaton, M.J., 1961. MNRAS 121, 471.

Cunto, W., Mendoza, C., Ochsenbein, F., Zeippen, C.J., 1993. A\&A, 275, L5. TOPbase at <http://cdsweb.u-strasbg.fr/topbase/topbase.html $>$.

Dalgarno, A., Lynn, N., 1957. Proc. Phys. Soc. London Sect. A 70, 802.

DeWitt, D.R. et al., 1994. Phys. Rev. A 50, 1257.

Drake, G.W.F., Martin, W.C., 1998. Can. J. Phys. 76, 679.

Drake, G.W.F., Morton, D.C., 2007. Astrophys. J. Suppl. 170, 251.

Eissner, W., Jones, M., Nussbaumer, H., 1974. Comput. Phys. Commun. 8, 270.

Fernley, A., Taylor, K.T., Seaton, M.J., 1987. J. Phys. B 20, 6457.

Hummer, D.G., Storey, P.J., 1998. MNRAS 297, 1073.

Hummer, D.G., Berrington, K.A., Eissner, W., Pradhan, A.K., Saraph, H.E., Tully, J.A., 1993. Astron. Astrophys. 279, 298.

Miller, D.L.i., Starace, A.F., 1980. J. Phys. B 13, L525.

Pequignot, D., Petitjean, P., Boisson, C., 1991. Astron. Astrophys. 251, 680. Nahar, S.N., 1996. Phys. Rev. A 53, 2417.

Nahar, S.N., 2004. Astrophys. J. Suppl. 156, 93.

Nahar, S.N., Pradhan, A.K., 1992a. PRL 68, 1488.

Nahar, S.N., Pradhan, A.K., 1992b. Phys. Rev. A 45, 7887.

Nahar, S.N., Pradhan, A.K., 1994. Phys. Rev. A 49, 1816.

Nahar, S.N., Pradhan, A.K., 1995. ApJ 447, 966.

NIST website: 〈http://physics.nist.gov/PhysRefData/ASD/index.html>.

Samson, J.A.R., 1976. Phys. Rep. 28, 303.

Seaton, M.J., 1987a. J. Phys. B 20, 6363.

Seaton, M.J., 1987b. It is known to the Opacity Project members that M.J. Seaton first explained and named PEC resonance as this prominent resonance became noticeable in excited state photoionization cross sections of $\mathrm{C}$ II from the calculations carried out under the OP. 
Tanabe, T. et al., 1991. Phys. Rev. A 45, 276.

The Opacity Project Team, 1995. The Opacity Project, 1.

The Opacity Project Team, 1996. The Opacity Project, Institute of Physics Publishing, 2.

Wendin, G., 1970. Phys. Lett. 33A, 16.

Wendin, G., 1971. J. Phys. B 4, 1080.

Yu, Y., Seaton, M.J., 1987. J. Phys. B 20, 6409. 